\title{
A statistical model of fatigue failure incorporating effects of specimen size and load amplitude on fatigue life
}

\section{Guian Qian \& Wei-Sheng Lei}

To cite this article: Guian Qian \& Wei-Sheng Lei (2019) A statistical model of fatigue failure incorporating effects of specimen size and load amplitude on fatigue life, Philosophical Magazine, 99:17, 2089-2125, DOI: 10.1080/14786435.2019.1609707

To link to this article: https://doi.org/10.1080/14786435.2019.1609707

曲 Published online: 01 May 2019.

Submit your article to this journal $\sqsubset$

Џ Article views: 49

View Crossmark data \lceil

Citing articles: 1 View citing articles $\square$ 


\title{
A statistical model of fatigue failure incorporating effects of specimen size and load amplitude on fatigue life
}

\author{
Guian Qian ${ }^{a}$ and Wei-Sheng Lei ${ }^{b}$ \\ a State Key Laboratory of Nonlinear Mechanics (LNM), Institute of Mechanics, Chinese Academy of \\ Sciences, Beijing, People's Republic of China; ${ }^{b}$ Applied Materials, Inc., Sunnyvale, CA, USA
}

\begin{abstract}
Among many contributing factors, the load range, number of load cycles and specimen geometry (including configuration and size) are three major variables for fatigue failure. Most existing statistical fatigue models deal with only one or two of these three variables. According to the statistical distribution of microcracks with respect to their size and spatial location, a weakest-link probabilistic model for fatigue failure is established to incorporate the combined effect of load range, number of load cycles and specimen size. The model reveals a compound parameter of load range and number of load cycles reminiscent of the empirical formulae of fatigue stress-life curve and its correlation with another compound parameter of cumulative failure probability and specimen size. Four sets of published fatigue test data are adopted to validate the model.
\end{abstract}

\section{ARTICLE HISTORY}

Received 11 October 2018

Accepted 10 April 2019

\section{KEYWORDS}

Fatigue; probabilistic model; microcrack distribution; size effect

\section{Introduction}

This work is devoted to the statistical modelling of fatigue behaviour for size scaling of fatigue limit and life. Fatigue damage is a type of brittle fracture under cyclic loading. Similar to brittle fracture under monotonous loading [1-3], fatigue damage [4-6] is also a random event and is specimen size dependent. The probabilistic nature of fatigue failure refers to the random fatigue life of a set of specimens with nominally identical geometry and dimensions subjected to cyclic loading with nominally identical amplitude and mode. The size effect denotes the inverse dependence of fatigue limit or fatigue life on the geometric size of a specimen. The random behaviour of brittle fracture is attributed to the stochastic distribution of microdefects such as microcracks in a material with respect to spatial location, orientation, size and shape, whereas the specimen size determines the number of defects in a specimen. These microdefects are either pre-existing or initiated and developed under cyclic loadings, 
which can be internal or surficial. The probabilistic nature of microdefect distribution and brittle fracture calls for statistical approaches to evaluating brittle fracture under either monotonic loading [1-3,7-10] or cyclic loading [4,1125]. To simplify the description and discussion, this work will only consider volumetric defects induced fatigue failure. For a solid of volume $(V)$ subjected to a cyclic load $(S)$ for a certain number of loading cycles $(N)$, its fatigue failure is a random event. That says, the cumulative probability $(P)$ for the occurrence of fatigue failure depends on the cyclic load $(S)$, number of loading cycles $(N)$, and specimen size $(V)$ (Figure 1). This allows us to describe the cumulative probability $(P)$ of fatigue failure of a solid as a function of cyclic load $(S)$, number of loading cycles $(N)$ and the volume $(V)$ of solid as follows:

$$
P=F(S, N, V)
$$

Here the cyclic load $(S)$ can be represented by either stress range $(\Delta \sigma)$ or strain range $(\Delta \varepsilon)$ at a material point, i.e. $S=\Delta \sigma=\left(\sigma_{\max }-\sigma_{\min }\right)=2 \sigma_{a}$, or $S=\Delta \varepsilon=\left(\varepsilon_{\max }-\varepsilon_{\min }\right)=2 \varepsilon_{a}$, where $\sigma_{\max }$ is the maximum stress, $\varepsilon_{\max }$ is the maximum strain, $\sigma_{\min }$ is the minimum stress, $\varepsilon_{\min }$ is the minimum strain, $\sigma_{\mathrm{a}}$ is stress amplitude, and $\varepsilon_{\mathrm{a}}$ is strain amplitude. The nominal value of a parameter will be identified by a subscript 'nom'. For example, $\Delta \sigma_{n o m}, \Delta \varepsilon_{n o m} \sigma_{a, n o m}$, and $\varepsilon_{a, n o m}$ refer to the nominal values of $\Delta \sigma, \Delta \varepsilon \sigma_{a}$, and $\varepsilon_{a}$ in sequence.

Derivation of the explicit formulation of Equation (1) is a much challenging effort even under the simplest uniaxial cyclic loading condition. By introducing $y=f\left(x_{1} \mid x_{2}, x_{3}\right)$ to denote $y$ as a function of variable $x_{1}$ with given values of variables $x_{2}$ and $x_{3}$, we may roughly sort the major studies on modelling fatigue behaviour into deterministic and statistical approaches (Figure 1).

\subsection{Deterministic models}

The deterministic models of $S-N$ (stress-life) curve [26-32] have been empirically proposed as fatigue failure criteria to depict the inverse $S-N$ correlation

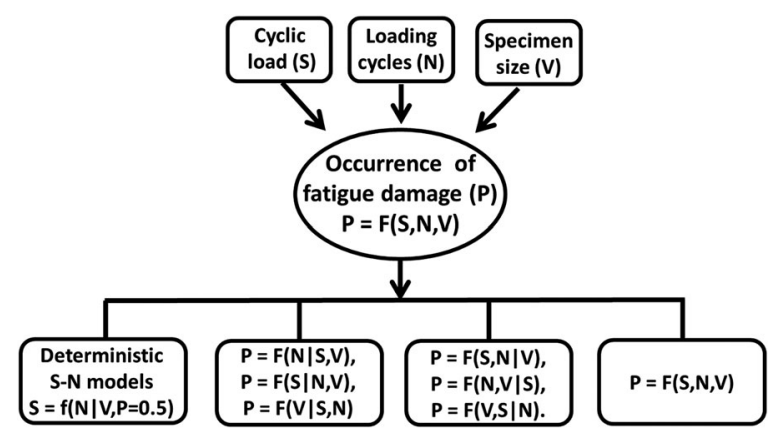

Figure 1. Three factors $(\mathrm{S}, \mathrm{N}, \mathrm{V})$ contributing to the occurrence of fatigue damage and four modelling approaches. 
for a given sized specimen ( $V$ is fixed), with the model parameters being fitted by experimental fatigue limits for a failure probability $P=50 \%$ :

$$
S=f(N \mid V, P=0.5)
$$

As examples, Table 1 lists some representative deterministic $S-N$ models, which adopt the stress and strain ranges $(\Delta \sigma, \Delta \varepsilon)$ as basic fatigue damage parameters. These empirical fatigue failure criteria can use either the nominal stress or strain range $\left(\Delta \sigma_{\text {nom }}, \Delta \varepsilon_{\text {nom }}\right)$ to characterise experimental fatigue limits of standard specimens or the local stress and strain ranges $(\Delta \sigma, \Delta \varepsilon)$ at a material point to develop statistical models of fatigue damage in various structural components. Given their wide adoptions validated by numerous experimental data, it is interesting to reveal the physical implication behind them. In this work, we will show that a physically sound statistical fatigue model should be able to derive or justify the $\mathrm{S}-\mathrm{N}$ relationships. Depending on the specific loading conditions, $S=\Delta \sigma$ as the first basic fatigue damage parameter can be either the principal tensile stress as usual, or the normal tensile stress component [21], or the shear stress component [4,21] on a critical plane. Similarly, $S=\Delta \varepsilon$ as the other basic fatigue damage parameter can be the tensile or shear strain component [31,32]. In addition to these two basic fatigue damage parameters, some compound variables have also been adopted as fatigue damage parameters to build the global or local deterministic fatigue failure criteria [15,21,25,33-36]. For examples,

$$
\begin{gathered}
S=\sigma_{\max } \cdot \varepsilon_{a} \\
S=\varepsilon_{a} \cdot\left(\frac{2}{1-R}\right)^{\eta} \\
S=\frac{\Delta \gamma}{2} \cdot\left(1+\frac{\sigma_{n, \max }}{\sigma_{y s}}\right)
\end{gathered}
$$

\begin{tabular}{|c|c|c|c|c|}
\hline \multirow[b]{2}{*}{ Model } & \multirow[b]{2}{*}{$S$} & \multicolumn{3}{|c|}{$S=f(N \mid V, P=0.5)$} \\
\hline & & Conventional expression & Equivalent expression & \\
\hline Wöhler (1870) [26] & $S=\Delta \sigma$ & $\Delta \sigma=A_{1}-B \log N$ & $\frac{\left(\Delta \sigma-A_{1}\right)}{\log N}=-B$ & \\
\hline Basquin (1910) [27] & & $\Delta \sigma=A_{1} N^{B}$ & $\Delta \sigma \cdot N^{-B}=A_{1}$ & \\
\hline Strohmeyer (1914) [28] & & $\Delta \sigma=A_{1} N^{B}+\Delta \sigma_{t h}$ & $\left(\Delta \sigma-\Delta \sigma_{t h}\right) \cdot N^{-B}=A_{1}$ & \\
\hline Palmgren (1924) [29] & & $\Delta \sigma=A_{1}(N+B)^{D}+\Delta \sigma_{t h}$ & $\left(\Delta \sigma-\Delta \sigma_{t h}\right) \cdot(N+B)^{-D}=A_{1}$ & \\
\hline Kohout \& Vechet (2001) [32] & & $\Delta \sigma=\Delta \sigma_{t h}\left(\frac{N+B}{N+A_{1}}\right)^{D}$ & $\left(\Delta \sigma-\Delta \sigma_{t h}\right) /\left[\left(\frac{N+B}{N+A_{1}}\right)^{D}-1\right]$ & $=\Delta \sigma_{t h}$ \\
\hline $\begin{array}{l}\text { Coffin-Manson (1954) } \\
{[30,31]}\end{array}$ & $S=\Delta \varepsilon_{p}$ & $\Delta \varepsilon_{p} / 2=\varepsilon_{f}^{\prime}(2 N)^{B}$ & $\left(\Delta \varepsilon_{p} / 2\right) \cdot(2 N)^{-B}=\varepsilon_{f}^{\prime}$ & \\
\hline
\end{tabular}

Table 1. Some representative deterministic S-N models [26-32].

Note: $\Delta \sigma_{\text {th }}=$ fatigue limit for an infinite number of cycles to fracture, i.e. permanent fatigue limit; $\Delta \varepsilon_{p} / 2=$ plastic strain amplitude, $\varepsilon_{f}^{\prime}=$ fatigue ductility coefficient, $A_{1}, B, D=$ constants. 


$$
\begin{gathered}
S=\Delta W_{t}=\frac{1-n^{\prime}}{1+n^{\prime}} \Delta \sigma \Delta \varepsilon_{p}+\frac{1}{2 E}\left(\frac{\Delta \sigma}{2}+\sigma_{m}\right)^{2} \\
S=\Delta K=Y \Delta \sigma_{e} \sqrt{\pi a} \\
S=W_{g}=\sum_{i, j} \int_{T}\left[\sigma_{i j}(t) \dot{\varepsilon}_{i j}(t)\right] \mathrm{d} t
\end{gathered}
$$

where $R=\sigma_{\min } / \sigma_{\max }$ is the stress ratio, $\eta$ is a fitting parameter for the sensitivity to mean stress $\sigma_{m}=\left(\sigma_{\max }+\sigma_{\min }\right) / 2, \Delta \gamma / 2$ is the shear strain amplitude, $\sigma_{n, \max }$ is the maximum normal stress on the critical plane, $\sigma_{y s}$ is the yield stress of material, $\chi$ is a material constant, $\Delta W_{t}$ is the total strain energy range, $\Delta \varepsilon_{p}$ is the plastic strain range, $n^{\prime}$ is the cyclic strain-hardening exponent, $E$ is the elastic modulous, $\Delta K$ is the range of stress intensity factor, $Y$ is a dimensionless parameter dependent on crack geometry, $a$ is crack size, $\Delta \sigma_{e}$ is the effective or equivalent stress range with $\Delta \sigma_{e}=\Delta \sigma$ for $R \geq 0$ and $\Delta \sigma_{e}=\sigma_{\max }$ for $R<0, W_{g}$ is the strain work density per loading cycle with the period $T, \sigma_{i j}(t)$ and $\dot{\varepsilon}_{i j}(t)$ are the instant stress component and strain rate at time $t$.

\subsection{Statistical models}

Refer to Figure 1 and Table 2, the major efforts on statistic modelling of fatigue can be summarised according to the number of variables out of the three variables $(S, N, V)$ being considered in a statistical model:

- $P$ as a function of a single variable given the other two: $P=F(N \mid S, V)$, $P=F(V \mid S, N), P=F(S \mid N, V)$, e.g. in $[12,23,24]$. This is an empirical approach that directly applies some classical statistical distribution functions to fit experimental data. The calibrated model parameters are not intrinsic material properties but contingent on the values of the other fixed variables. For example, refer to Table 2, Zhao and Liu [23] applied the ordinary 3-parameter Weibull distribution function to describe the statistical distribution of fatigue life $(\mathrm{N})$ of specimens with nominally identical geometrical dimensions at different nominal stress amplitudes. This resulted in different values of Weibull parameters for each nominal stress amplitude. Moreover, when specimen size changes, the estimated values of Weibull parameters will also change. This precludes the predictability of such a single-variable statistical model for other test conditions involving different specimen sizes or stress amplitudes. In Section 4.2, the experimental data in [23] will be re-analysed according to the newly proposed model in Section 3.

- $P$ as a function of two variables given the other one: $P=F(S, N \mid V)$, $P=F(N, V \mid S), \quad P=F(S, V \mid N), \quad$ e.g. in [4,11,12,15,17-23]. Specifically, $P=F(S, N \mid V)$ reveals the ongoing effort for probabilistic stress-life (P-S-N) 
Table 2. Typical probabilistic models for fatigue incorporating number of cycles $(N)$, load amplitude $(S)$, and size $(V)$ effect $[11,12,14-24]$.

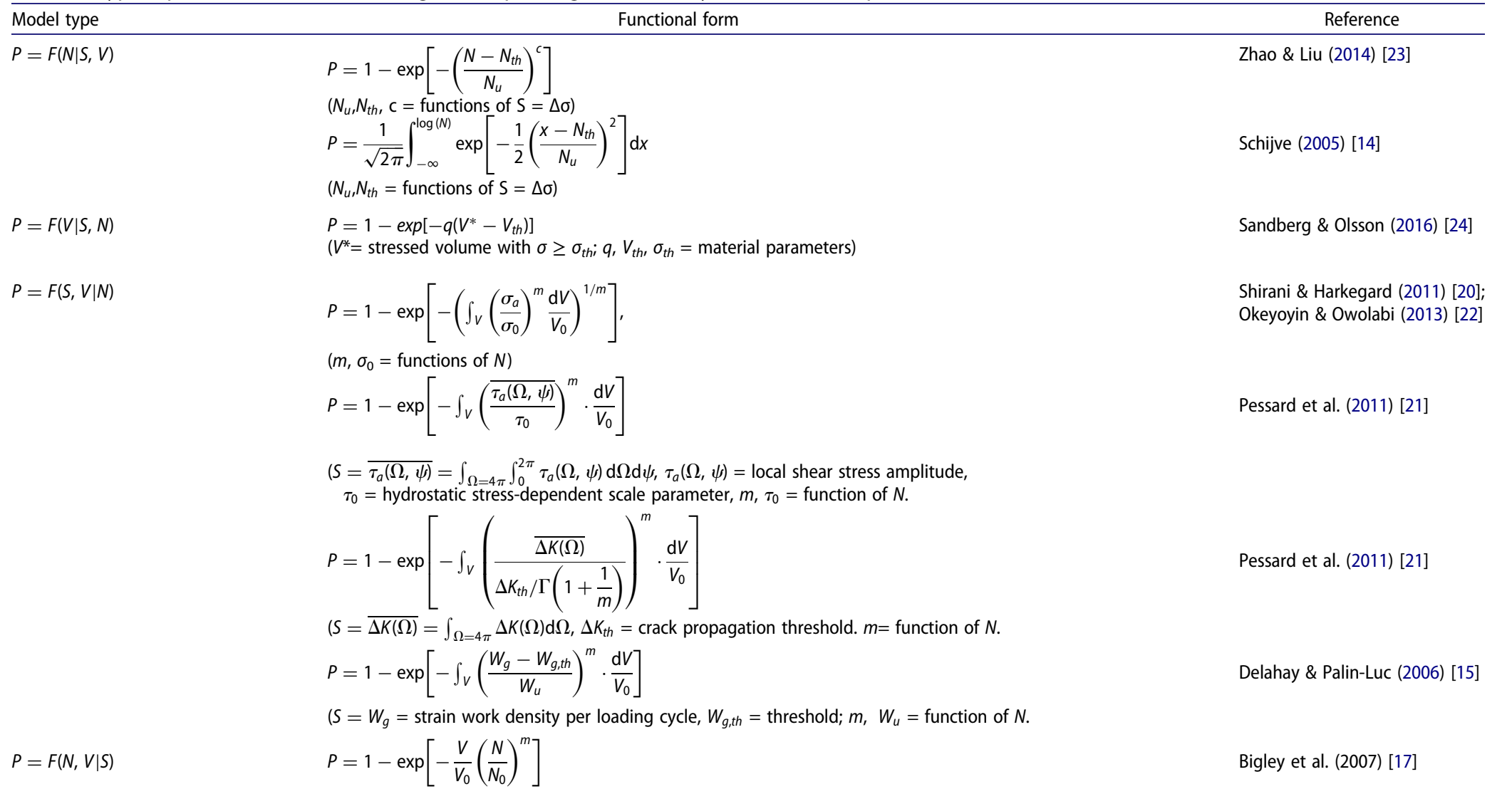


( $m, \sigma_{0}=$ functions of $N$ )

$P=1-\exp \left[-\int_{V}\left(\frac{\log (N)}{\log \left(N_{0}\right)}\right)^{\left(c / \log \left(N_{0}\right)\right)} \cdot \frac{\mathrm{d} V}{V_{0}}\right]$

Karolczuk (2008) [18]

$\left(N_{0}=\right.$ a function of $\left.\Delta \sigma\right)$

$P=F(N, A \mid S)$

$P=1-\exp \left\{-\frac{A}{A_{0}}\left[\left(\frac{N}{N_{0}}\right)^{m}-\left(\frac{N_{i}}{N_{0}}\right)^{m}\right]\right\}$

Schweiger \& Heckel (1986) [12]

( $N_{0}=$ a function of $\Delta \sigma, A=$ surface area, $A_{0}=$ reference area)

$P=F(S, N \mid V)$

$P=F\left(\frac{\sigma_{a}-\emptyset(N)-D}{\sigma_{0}}\right)$,

Bastenaire [11]

$A_{2} \exp [C \varnothing(N)]=(N+B) \varphi(N)$,

$N \rightarrow \infty, \emptyset(N) \rightarrow 0$

$P=1-\exp \left\{-\left[\frac{\left(\log \left(\frac{N}{N_{0}}\right)-B\right)\left(\frac{\Delta \sigma}{\sigma_{0}}-C\right)-E}{D}\right]^{A_{2}}\right\}$

Castillo et al. (2009) [19]

$\left(N_{0}, \sigma_{0}=\right.$ scale parameters; $A_{2}, B, C, D, E=$ functions of $\sigma_{\min } / \sigma_{0}$ and $\left.\sigma_{\max } / \sigma_{0}\right)$

$P=F(S, N, L)$

$P=1-\exp \left\{-\frac{L}{L_{0}}\left[\frac{\left(\log \left(\frac{N}{N_{0}}\right)-B\right)\left(\frac{\Delta \sigma}{\sigma_{0}}-C\right)-E}{D}\right]^{A_{2}}\right\}$ (uniaxial tension;

Castillo et al. (2006) [16]

$L=$ specimen length, $L_{0}=$ reference length; $N_{0}, \sigma_{0}=$ scale parameters;

$A_{2}, \mathrm{~B}, \mathrm{C}, \mathrm{D}, \mathrm{E}=$ functions of $\sigma_{\min } / \sigma_{0}$ and $\sigma_{\max } / \sigma_{0}$ ) 
studies using a given specimen configuration and size (V is fixed), e.g. in [4,11]. Most statistical models in this category adopt a basic fatigue damage parameter as in the deterministic S-N relationship in Table 1 or a compound fatigue damage parameter as showcased in Equations (3)-(8) to directly modify the Weibull statistical fracture model. Refer to Table 2, take the models of $P=F(S, V \mid N)$ for examples, which can be generically described as below:

$$
P=1-\exp \left[-\int_{V}\left(\frac{\bar{S}-S_{t h}}{S_{u}}\right)^{m} \cdot \frac{\mathrm{d} V}{V_{0}}\right]
$$

where $\bar{S}=\frac{1}{4 \pi} \int_{=4 \pi} S d$ is the average value of a fatigue damage parameter $S$ on all the possible material planes in a reference volume $V_{0}$ defined by the solid angle $\Omega$ in a unit sphere. $\bar{S}=S$ when the local value of $S$ is independent of spatial orientation $(\Omega)$, such as the princ.pal stress/strain components. When the threshold $S_{t h}=0$, Equation (9) reduces to a twoparameter model. Both the two basic fatigue damage parameters $(S=\Delta \sigma ; \Delta \varepsilon)$ and the compound fatigue damage parameters in Equations (3)-(8) have been introduced into Equation (9) in relevant studies. To name a few, the two-parameter Weibull model adopting the amplitude of maximum tensile principal stress $\left(S=\sigma_{a}\right)$ as the local fatigue damage parameter were used in [20,22]. Pessard et al. [21] also employed the two-parameter Weibull model for fatigue behaviour in a forged steel by coupling two crack initiation mechanisms: the amplitude of local shear stress $\left(S=\tau_{a}\right.$ ) on a glide system in a grain was adopted as the fatigue damage parameter for crack initiation in the material matrix, while the range of local stress intensity factor $(S=\Delta K)$ in Equation (7) due to the normal stress component $\left(S=\sigma_{n}\right)$ on a crack surface was used as the fatigue damage parameter for crack initiation from breakage of non-metallic inclusions. Since the local stress intensity factor $(\Delta K)$ only takes the normal stress component $\left(\sigma_{n}\right)$ acting on the crack surface into account, the $S=\Delta K$ based model is a modified Weibull model for the normal stress component $\left(\sigma_{n}\right)$ [37]. Delahay and Palin-Luc [15] proposed a three-parameter Weibull model in terms of the strain work density per loading cycle $\left(W_{g}\right)$ at a material point defined in Equation (8), which gave inconsistent (underestimate, overestimate or mixed) predictions compared to experimental results.

Note that any model via the direct combination of Equations (3)-(8) with Equation (9) remains as an assumption based on physical understandings of fatigue mechanisms. As analysed in detail in [1], regardless of the specific definition of parameter $S$ being taken (e.g. in Equations (3)-(8)), the Weibull model Equation (9) itself is a weakest link model based on the assumption 
that the critical value of $S$, here below denoted as $S_{c}$, is an intrinsic material property with the following probability density function (PDF):

$$
g\left(S_{c}\right)=\frac{m}{S_{u}}\left(\frac{S_{c}-S_{t h}}{S_{u}}\right)^{m-1} \cdot \exp \left[-\left(\frac{S_{c}-S_{t h}}{S_{u}}\right)^{m}\right]
$$

It is almost impossible to experimentally measure the PDF of $S_{c}$ for any parameter $S$ defined in Equations (3)-(8).

For example, Correia, et al. [25] proposed the following purely empirical probabilistic damage-life $(P-S-N)$ model:

$$
P=F(S, N \mid V)=1-\exp \left\{-\left[\frac{\log \left(N / N_{0}\right) \cdot \log \left(S / S_{0}\right)-\lambda}{\delta}\right]^{m}\right\}
$$

where $N_{0}$ and $S_{0}$ are two scale parameters to ensure dimensional consistency of the ratios $N / N_{0}$ and $S / S_{0}, \lambda$ is a non-dimensional constant that satisfies $\log \left(N / N_{0}\right) \cdot \log \left(S / S_{0}\right) \geq \lambda, \delta$ is also a scale parameter. Various definitions of fatigue parameter $S$ including $S=\Delta \sigma, S=\Delta \varepsilon_{p}$, and those in Equations (3)(8) can be adopted in Equation (11). When an arbitrary value $0 \leq P \leq 1$ is assigned to $P$, a corresponding $S-N$ correlation is obtained, instead of keeping $P=0.5$ as in Equation (2).

These models are in nature the Weibull model for a newly defined variable $S$ other than the two basic fatigue damage parameters $(S=\Delta \sigma ; \Delta \varepsilon)$. They are all two-variable statistical models, since all Equations (3)-(8) do not contain the number of cycles $(N)$. Therefore, like the preceding single-variable statistical models, the calibrated parameters of these two-variable statistical models are also contingent on the specific value of the third variable being fixed instead of intrinsic material properties, which prevents the transferability of the calibrated models to other scenarios with different values of the third variable.

- $\mathrm{P}$ as a function of all the three variables $(S, N, V), P=F(S, N, V)$, e.g. in $[13,16]$. In contrast to various single- or two-variable statistical models, much less work has been done on this third category. Castillo et al. [16] developed a model of all three variables $(S, N$ and specimen length $L$ ) in the very specific case of uniaxial smooth tension of a wire. It resulted from combining Weibull model Equation (9) with the following newly defined parameter $S$ as the function of both stress range $(\Delta \sigma)$ and loading cycles $(N)$ :

$$
S=\left(\log \left(\frac{N}{N_{0}}\right)-B\right)\left(\frac{\Delta \sigma}{\sigma_{0}}-C\right)
$$

where $B, C$, and $\sigma_{0}$ are constants.

Chantier, et al. [13] developed a statistical model to predict the very high cycle fatigue (VHCF) behaviour of cast iron structures. This model differentiated itself 
from the preceding models by starting from the basic formulation of weakest link statistics instead of Weibull model Equation (9) and considering the size distribution and growth rate of microcracks. However, due to the complexity of the models for both the size distribution and growth rate of microcracks, the combined effects of loading amplitude $(\Delta \sigma)$, loading cycles $(\mathrm{N})$ and specimen size $(\mathrm{V})$ on the cumulative probability of fatigue failure cannot be explicitly formulated. In addition, a wrong expression for microcrack size distribution function was taken in their work. Further formulation for an explicit representation of the size (V) effect by simplifying the size distribution function of microcracks involves wrong mathematical speculation. More detailed discussions on the work of [13] will be given in Section 5 Discussions.

The preceding description draws attentions to two points:

(1) The statistical fatigue models. Most statistical models for fatigue failure as cited in Table 2 directly adopt some classical empirical distribution function (e.g. Weibull or Gaussian) for the cumulative probability. The most common practice is to assume that the PDF of the critical value $S_{c}$ of some fatigue parameter $S$ is described by Weibull model in Equation (10). In contrast, statistical modelling of brittle fracture under monotonic loading commonly adopts the so-called 'Local Approach' [1-3,7-10], a fracture physics-based methodology that combines micromechanics and statistical distribution of microcracks. This motivates this work to apply the Local Approach for fatigue modelling.

(2) The empirical S-N models. On one hand, most empirical S-N models in Table 1 suggest a combined effect of $\mathrm{N}$ and $\mathrm{S}$ in a form given in Equation (2). Given their wide adoptions validated by numerous experimental data, it is interesting to reveal the physical implication behind them. On the other hand, an empirical deterministic S-N relationship (e.g. Basquin equation [27]) in Table 1 is always adopted as the input condition to build the statistical fatigue models in Table 2. In the following sessions, we will show that a physically sound statistical fatigue model should be able to derive or justify the S-N relationships.

Recently, within the framework of Local Approach, a generalised weakest-link model of brittle fracture [2] for monotonous loading was developed. It was validated on a wide variety of materials including gamma titanium aluminium alloy, aluminium foam, ceramics, nuclear grade graphite, wood, coal, rock, basalt, sugar, and potash $[2,38,39]$. This work aims to explore the applicability of this generalised weakest-link model to fatigue failure along the following path:

- First, the generalised weakest-link model for brittle fracture induced by monotonous loading will be briefly overviewed;

- Second, the model will be extended to fatigue failure;

- Third, a few case studies will be presented for preliminary validation; 
- Fourth, some critical assumptions and treatments in the statistical model of fatigue failure will be discussed;

- Fifth, summary and conclusions will be drawn.

\subsection{A brief introduction to the generalised weakest-link model of brittle fracture under monotonous loading}

The Local Approach [1-3,7-10] attempts to formulate statistical models of brittle fracture based on the physical understanding of the microcrack nucleation and propagation processes in combination with the detailed micromechanics analysis. The statistical distribution of microcracks needs to be characterised in terms of spatial location, spatial orientation, shape and size $[1,8]$. A generalised weakest-link model of brittle fracture was recently proposed to evaluate a wide spectrum of quasi-brittle materials under monotonic loading [2]. The model formulates the cumulative failure probability $P$ of a solid with volume $V$ subjected to the stress $\langle\sigma\rangle$, as follows:

$$
P=1-\exp \left\{\int_{V} \ln \left[1-p\left(, a, V_{0}\right)\right] \cdot \frac{\partial n(V)}{\partial V} \cdot \delta V\right\}
$$

where $n(V)$ is the number of non-interactive microcraks in a volume $V, \delta V$ is a differential volume element, so that the number of microcracks inside $\delta V$ is expressed as $n(V)=[\partial n(V) / \partial V] \cdot \delta V, p\left(\sigma, a, V_{0}\right)$ is the fracture probability of a reference volume element $V_{0}$ embedded with a microcrack of size $a$ and subjected to a stress state $\langle\sigma\rangle$.

Assume a power-law spatial distribution of microcracks as below:

$$
n(V)=k V^{\beta_{1}}=\left(\frac{V}{V_{0}}\right)^{\beta_{1}}, \quad k=\frac{1}{V_{0}^{\beta_{1}}}, \beta_{1}>0
$$

where $\beta_{1}$ and $k$ are constants with $\beta_{1}, k>0, k$ has the unit of $V^{-\beta_{1}}$ for dimensional consistency, Equation (13) reduces to

$$
P=1-\exp \left\{\beta_{1}\left(\frac{V}{V_{0}}\right)^{\beta_{1}-1} \int_{V} \ln \left[1-p\left(, a, V_{0}\right)\right] \cdot \frac{V}{V_{0}}\right\}
$$

Under the simplest case $\beta_{1}=1$, which corresponds to the uniform spatial distribution of microcracks, there is:

$$
n(V)=k V=\frac{V}{V_{0}}, \quad k=\frac{1}{V_{0}}
$$

Accordingly, Equation (15) reduces to

$$
P=1-\exp \left\{\int_{V} \ln \left[1-p\left(\sigma, a, V_{0}\right)\right] \frac{V}{V_{0}}\right\}
$$


Under monotonic loading, Equation (15) is applicable to a variety of quasibrittle materials $[2,38,39]$, while Equation (17) has been adopted for statistical modelling of cleavage fracture of ferritic steels $[1,3,8,9]$.

According to Section 1, since fatigue failure is much similar to brittle failure under monotonic loading in the aspects of random occurrence and size effect. In principle, Equation (15) or (17) should be also applicable to fatigue failure.

As a preliminary effort and for simplicity, this work will extend Equation (17) for the uniform spatial distribution of defects $\left(\beta_{1}=1\right)$ to fatigue failure. The examples provided in this work all fit $\beta_{1}=1$. We will explore fatigue failure due to non-uniform spatial flaw distribution $\left(\beta_{1} \neq 1\right)$ in future studies.

\section{Extension of the model to fatigue failure}

This session will mainly lay out the deduction process of the statistical fatigue model. The critical assumptions and mathematical treatments adopted in the model will be discussed in a separate session.

\subsection{Basic considerations}

To extend Equation (17) from monotonic loading to cyclic loading, a key effort is needed to pertinently formulate $p\left(\sigma, a, V_{0}\right)$, the fracture probability of a reference volume element $V_{0}$ in a stress state $\langle\sigma\rangle \cdot p\left(\sigma, a, V_{0}\right)$ can be determined as below $[1,3,8,40]$ :

$$
p\left(\sigma, a, V_{0}\right)=\int_{\sigma_{t h}}^{\sigma_{e, \max }} F\left(\sigma_{e} \geq s\right) \cdot g(s) \cdot \mathrm{d} s
$$

where $\sigma_{e \text {, max }}$ is the upper bound value of the equivalent stress $\sigma_{\mathrm{e}}, F\left(\sigma_{e} \geq s\right)$ is the fracture probability of an existing microcrack, $g(s)$ is the probability density function (PDF) of microcracks with respect to the critical fracture strength $(s)$.

Under the simplest uniaxial (tensile or shear) stress criterion for unstable microcrack propagation, such as the maximum tensile principal stress criterion $\left(\sigma_{e}=\sigma_{1}\right), F\left(\sigma_{e}=\sigma_{1} \geq s\right)=1$, Equation (18) reduces to

$$
p\left(\sigma, a, V_{0}\right)=\int_{\sigma_{t h}}^{\sigma_{1, \max }} g(s) \cdot \mathrm{d} s \equiv \int_{a\left(\sigma_{1, \max }\right)}^{a_{\max }\left(\sigma_{t h}\right)} f(a) \mathrm{d} a
$$

where $f(a)$ is the PDF of microcracks with respect to microcrack size $(a)$.

There are some distinctive differences between the monotonic loading induced brittle fracture and the cyclic loading induced fatigue failure, which will affect the formulation process of $p\left(\sigma, a, V_{0}\right)$. Brittle fracture due to monotonic loading is usually described as a two-step process namely, microcrack nucleation and propagation. For brittle and quasi- 
brittle materials such as ceramics, microcracks can be pre-existing or initiated at initial flaws [2,38], while for ductile materials such as steels, microcracks are often nucleated because of plastic deformation $[1,3,8,9]$. Brittle fracture occurs as soon as one microcrack propagates unstably. Therefore, the statistical distribution of nucleated microcracks plays a critical role while the possibility of their stable growth or propagation prior to the occurrence of unstable propagation is neglected [40]. The fatigue process generally involves microcrack evolution and macrocrack propagation $[5,6,13,41]$. Microcrack evolution includes microcrack initiation and subsequent stable growth or propagation of microcracks. The initiation of microcracks may occur directly at initial flaws in materials or begin with cyclic loading induced microstructural changes leading to permanent damage and then nucleation of microcracks in materials. The nucleated microcracks will propagate stably and a dominant macroscopic crack will be formed. The stable growth or propagation of nucleated microcracks may involve coalescence of microcracks. Subsequently, the macrocrack usually propagates unstably in brittle materials, but it will first experience a stable growth phase prior to unstable propagation in ductile materials. However, as stated in $[13,41]$, in the framework of weakest link theory, both the coalescence of microcracks and the stable/unstable macrocrack propagation will be neglected. On the one hand, this treatment greatly simplifies mathematical treatment, which is almost necessary to implement the weakest link theory. On the other hand, for high cycle fatigue (HCF) and VHCF, macrocrack propagation only takes a minor or negligible portion of the component life. While realistic microcracks may have various irregular geometrical shapes, it is a common practice to assume all microcracks to be penny shaped to capture their major physical characteristics as stress concentrators. The negligence of microcrack coalescence is due to the same consideration. The validity of these simplification treatments has to be examined by case studies.

Based on the above discussion, microscopically, we assume that under cyclic loading, a population of mutually independent microcracks of initial size $a_{i} \geq 0$ are pre-existing. Note that $a_{i}=0$ represents the scenario that the initial microcrack size is negligible. These microcracks grow with increase of loading cycles; Eventually, fatigue fracture occurs as soon as one microcrack reaches a critical size and then propagates unstably. This suggests that the growth behaviour of a microcrack under cyclic loading and the statistical distribution of the instant microcrack size $a$ need to be quantified. This physical understanding will guide the formulation process of $p\left(\sigma, a, V_{0}\right)$ and extension of Equation (17) to fatigue fracture. Also, the maximum principal stress criterion $\left(\sigma_{e q}=\sigma_{1}\right)$ will be adopted so that the formulation process of $p\left(\sigma, a, V_{0}\right)$ will be based on its simple definition in Equation (19). Figure 2 summarises the thought process for model extension. 


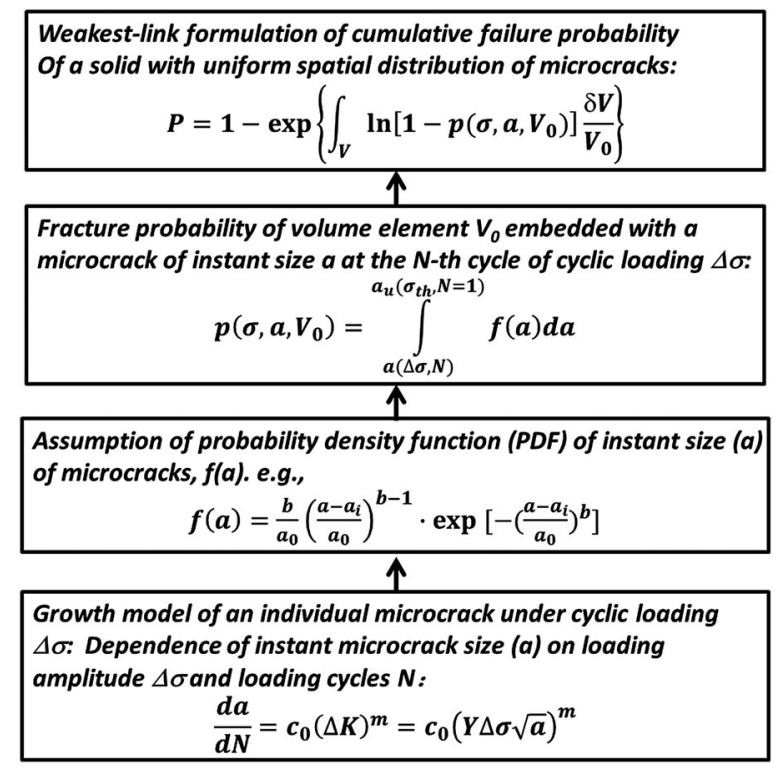

Figure 2. Framework of extending Equation (17) from monotonic loading to cyclic loading.

\subsection{Fracture probability of a microcrack under cyclic loading}

The fracture probability of an individual microcrack of an instant size $a$ residing in an elemental volume $V_{0}$ at the $N$-th cycle of applied load range $\Delta \sigma$ is given as

$$
p\left(\Delta \sigma, a, V_{0}\right)=\int_{a(\Delta \sigma, N)}^{a_{\max }\left(\sigma_{t h}, N=1\right)} f(a) \mathrm{d} a
$$

$f(a)$ is confined to the following normalisation requirement

$$
\int_{a_{i}(\Delta \sigma, N=0)}^{a_{\max }\left(\sigma_{t h}, N=1\right)} f(a) \mathrm{d} a=1
$$

Here $\sigma_{t h}$ is the threshold stress under monotonic loading $(N=1), a_{\max }$ is the upper bound microcrack size corresponding to the monotonic threshold stress $\sigma_{t h}$.

The exact statistical distribution of the instant microcrack size $a$ after $N$ cycles of loading is usually unknown. Here, we adopt the three-parameter Weibull PDF to describe the statistical distribution of instant microcrack size $a$ as below,

$$
f(a)=\frac{b}{a_{0}}\left(\frac{a-a_{i}}{a_{0}}\right)^{b-1} \cdot \exp \left[-\left(\frac{a-a_{i}}{a_{0}}\right)^{b}\right]
$$


where $a_{0}$ is a scale parameter, $b$ is a shape factor. Due to Equation (20), there is

$$
p\left(\Delta \sigma, a, V_{0}\right)=\int_{a}^{a_{\max } \rightarrow \infty} f(a) \mathrm{d} a=1-\exp \left[-\left(\frac{a-a_{i}}{a_{0}}\right)^{b}\right]
$$

Now the combination of Equations (23) for $p\left(\Delta \sigma, a, V_{0}\right)$ and (15) formulates the cumulative probability model for fatigue failure in terms of instant microcrack size a under the $N$-th cycle of applied loading:

$$
P=1-\exp \left\{\beta_{1}\left(\frac{V}{V_{0}}\right)^{\beta_{1}-1} \int_{V}\left(\frac{a-a_{i}}{a_{0}}\right)^{b} \frac{\delta V}{V_{0}}\right\}
$$

For the uniform spatial distribution of microcracks $\left(\beta_{1}=1\right)$, there is:

$$
1-P=\exp \left[-\int_{V}\left(\frac{a-a_{i}}{a_{0}}\right)^{b} \frac{\delta V}{V_{0}}\right]
$$

The adoption of the Weibull distribution function in Equation (22) for the statistical distribution of the instant microcrack size $a$ has two merits: First, as shown in Figure 3, by adjusting the values of parameters $a_{i}$ and $b$, the Weibull distribution is flexible to characterise different distribution characteristics of instant microcrack size a, including power-law type, symmetrical and non-symmetrical type distributions. Second, as shown in Equations (23)-(25), it facilitates mathematical treatments. The following sessions will focus on Equation (25) for elaboration.

The next step is to formulate the instant microcrack size $a$ as a function of loading range $\Delta \sigma$ and number of loading cycles $N$.

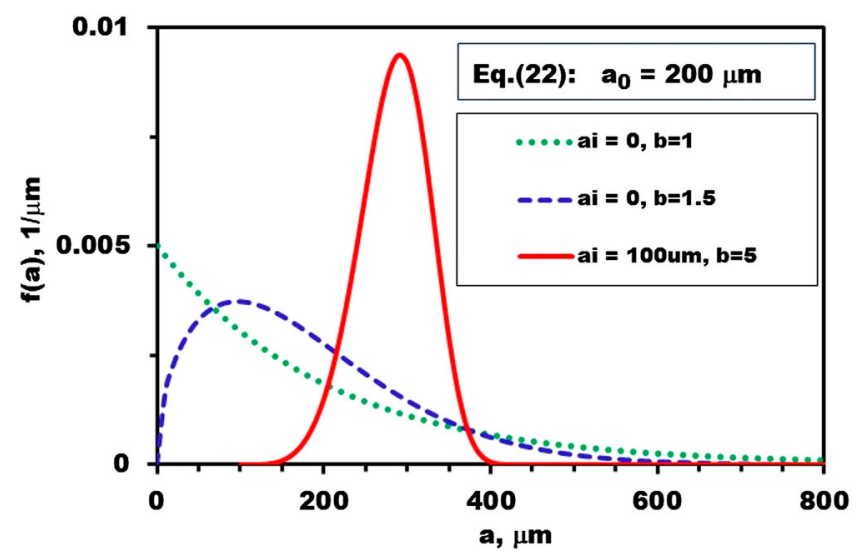

Figure 3. Weibull distribution of instant microcrack size with different model parameters ( $b$ and $a_{i}$ ). 


\subsection{Growth behaviour of an arbitrary microcrack under cyclic loading}

The growth behaviour of microcracks is a rather complex topic. The generally accepted physical understanding of microcrack growth dynamics is that the size of microcrack $(a)$ increases with loading cycles $(N)$ and applied load $(\Delta \sigma)$; alternatively, the general model of growth rate $\mathrm{d} a / \mathrm{d} N$ as a function of the range of stress intensity factor $\Delta K$ is as below:

$$
\frac{\mathrm{d} a}{\mathrm{~d} N}=H(\Delta K) \stackrel{\Delta \sigma=\text { Const } \mathrm{d} a}{\Rightarrow} \frac{\mathrm{d} N}{=h(a \mid \Delta \sigma)}
$$

where $\Delta K=K_{\max }-K_{\min }=Y \Delta \sigma \sqrt{\pi a}, K_{\max }$ and $K_{\min }$ are the maximum and the minimum stress intensity factor, respectively, However, the exact mathematical expression is unknown for real materials. It is reasonable to expect that the size of a microcrack monotonically increases with the number of loading cycles. Many mathematical functions are available to describe monotonous increasing curves. It is advantageous to adopt some relatively simple mathematical function to describe the growth behaviour of microcracks under cyclic loading to build a conceptual model that can be evaluated and improved via experiments. The power function $y=c_{1}\left(x-x_{t h}\right)^{c_{2}}$ is the simplest function for this purpose, with the constants $c_{1}, c_{2}, x_{t h}>0$. As $c_{2}=1$, it reduces to the linear function $y=c_{1}\left(x-x_{t h}\right)$. For example, Tomkins [42] used the following linear model to describe fatigue crack growth rate under low-cycle fatigue (LCF) which involves a remarkable plastic strain zone,

$$
\frac{\mathrm{d} a}{\mathrm{~d} N}=\left[k_{g 0}\left(\varepsilon_{p, a}\right)^{d}\right] a
$$

or

$$
a=a_{i} \cdot \exp \left[k_{g 0}\left(\varepsilon_{p, a}\right)^{d} \cdot N\right]
$$

where $k_{g 0}$ and $d$ are material parameters, $\varepsilon_{p, a}$ is the plastic strain amplitude.

The conventional Paris' law for the growth behaviour of a macro-crack under cyclic loading is such a power function. It describes the growth rate of a crack with instant size $a$ at the $N$-th loading cycle as a power function of crack size,

$$
\frac{\mathrm{d} a}{\mathrm{~d} N}=c_{0}(\Delta K)^{m}=c_{0}(Y \Delta \sigma \sqrt{a})^{m}
$$

where $m$ and $c_{0}$ are material constants, also known as the Paris' parameters.The conventional Paris' law in Equation (29) and its various modified expressions have also been adopted to describe the growth rate of a microcrack, which will be exemplified in Section 5 Discussions. For the simplicity of mathematical treatment, here we adopt Equation (29) and assume all microcracks are selfsimilar so that the parameter $Y$ is independent of microcrack size (a). Alternatively, Equation (29) can be expanded to the following power function for more 
generic situations:

$$
\frac{\mathrm{d} a}{\mathrm{~d} N}=\left[\lambda_{1}(\Delta \sigma)^{2 \eta_{1}}\right] a^{\eta_{2}}
$$

where $\eta_{1}, \eta_{2}$, and $\lambda_{1}$ are material constants, with either $\eta_{1}=\eta_{2}$ or $\eta_{1} \neq \eta_{2}$ being possible. One example of $\eta_{1} \neq \eta_{2}$ is in analogy to Equation (27) for a linear growth rate with respect to $a$

Rearranging and integrating Equation (29) yields

$$
\begin{aligned}
N & =\int_{0}^{N} \mathrm{~d} N=\int_{a_{i} 0}^{a} \frac{\mathrm{d} a}{{ }_{0}(Y \Delta K)^{m}} \\
& =\left\{\begin{array}{cc}
\frac{1}{\lambda_{2}(\Delta \sigma)^{m}} \ln \left(\frac{a}{a_{i}}\right) & \left(m=2, a_{i}>0\right) \\
\frac{1}{\lambda_{3}(\Delta \sigma)^{m}}\left(a^{(2-m / 2)}-a_{i}^{(2-m / 2)}\right) & \left(m \neq 2, a_{i} \geq 0\right)
\end{array}\right.
\end{aligned}
$$

with $\lambda_{2}=c_{0}(Y \sqrt{\pi})^{m}, \lambda_{3}=\frac{(2-m) c_{0}}{2}$.

Equations $(31 \mathrm{a}, \mathrm{b})$ are rearranged as

$$
\begin{aligned}
a & =F\left((\Delta \sigma)^{m} N\right) \\
& =\left\{\begin{array}{cc}
a_{i} \exp \left[{ }_{2}(\Delta \sigma)^{m} N\right] & \left(m=2, a_{i}>0\right) \\
{\left[a_{i}^{(2-m / 2)}+{ }_{3}(\Delta \sigma)^{m} N\right]^{(2 / 2-m)}} & \left(m \neq 2, a_{i} \geq 0\right)
\end{array}\right.
\end{aligned}
$$

Here $a=F\left((\Delta \sigma)^{m} N\right)$ denotes that the instant microcrack size $a$ is a function of the compound parameter $(\Delta \sigma)^{m} N$. Regardless of the complex expressions involved, the key takeaway from Equation $(32 \mathrm{a}, \mathrm{b})$ is that under the power-law assumption of microcrack growth dynamics in Equation (29), the instant size $(a)$ of a microcrack under cyclic loading increases with the compound parameter $(\Delta \sigma)^{m} N$. Substitution of Equation $(32 \mathrm{a}, \mathrm{b})$ in Equation (25) yields

$$
1-P=\exp \left\{-\int_{V}\left[\frac{F\left((\Delta \sigma)^{m} N\right)-a_{i}}{a_{0}}\right]^{b} \frac{\delta V}{V_{0}}\right\}
$$

Note that in Equation (33) we use the generic term $F\left((\Delta \sigma)^{m} N\right)$ rather than its explicit expressions in Equations $(32 \mathrm{a}, \mathrm{b})$ to highlight the key contribution of the compound parameter $(\Delta \sigma)^{m} N$. Equation (33) incorporates the contributions of all the three variables $S=\Delta \sigma, N$ and $V$ to the cumulative failure probability $P$. Furthermore, the compound parameter $(\Delta \sigma)^{m} N$ collectively quantifies the driving force for fatigue fracture process. Each value of this compound parameter corresponds to a specific failure probability $P$ for a given sized specimen ( $V$ is fixed) in a specific fatigue test, i.e.

$$
(\Delta \sigma)^{m} N=\operatorname{Const}(P \mid V)
$$


where $\operatorname{Const}(P \mid V)$ is a constant dependent on $P$ and $V$. Equation (34) is reminiscent of Equation (2) and some empirical formulas in Table 1, with $P$ being extended to any value including $P=0.5$.

According to the first mean value theorem for integrals, Equation (33) reduces to

$$
1-P=\exp \left\{-\frac{V}{V_{0}}\left[\frac{F\left(\eta_{3}\left(\Delta \sigma_{\text {nom }}\right)^{m} N\right)-a_{i}}{a_{0}}\right]^{b}\right\}
$$

where $\eta_{3}>0$ is a coefficient that defines the average value, $F\left(\eta_{3}\left(\Delta \sigma_{\text {nom }}\right)^{m} N\right)$, of the integral in Equation (33) as below:

$$
\frac{1}{V} \int_{V}\left[F\left((\Delta \sigma)^{m} N\right)-a_{i}\right]^{b} \delta V=\left[F\left(\eta_{3}\left(\Delta \sigma_{n o m}\right)^{m} N\right)-a_{i}\right]^{b}
$$

Note that in the integral in Equation (33), the generic term $F\left((\Delta \sigma)^{m} N\right)$ involves the local stress amplitude $\Delta \sigma$, while in the average value $\left(\eta_{3}\left(\Delta \sigma_{n o m}\right)^{m} N\right)$, the nominal stress $\Delta \sigma_{\text {nom }}$ is adopted due to the first mean value theorem for integrals.

In equivalence, Equation (35) is rewritten as

$$
\left\{\frac{1}{V} \ln \left[\frac{1}{(1-P)}\right]\right\}^{1 / b}=\frac{1}{V_{0}^{1 / b}}\left[\frac{F\left(\eta_{3}\left(\Delta \sigma_{\text {nom }}\right)^{m} N\right)-a_{i}}{a_{0}}\right]
$$

Particularly, for a smooth cylindrical specimen subjected to cyclic uniaxial tension/compression, due to the uniform stress distribution inside the specimen, Equation (33) reduces to

$$
1-P=\exp \left\{-\frac{V}{V_{0}}\left[\frac{F\left(\left(\Delta \sigma_{\text {nот }}\right)^{m} N\right)-a_{i}}{a_{0}}\right]^{b}\right\}
$$

or in equivalence,

$$
\left\{\frac{1}{V} \ln \left[\frac{1}{(1-P)}\right]\right\}^{1 / b}=\frac{1}{V_{0}^{1 / b}}\left[\frac{F\left(\left(\Delta \sigma_{\text {nom }}\right)^{m} N\right)-a_{i}}{a_{0}}\right]
$$

Equations (37) and (39) suggest us to synchronise the experimental data by evaluating the correlation between the two compound parameters $\frac{1}{V} \ln \left[\frac{1}{(1-P)}\right]$ and $\left(\Delta \sigma_{\text {nom }}\right)^{m} N$. Note that Equation (37) is applicable to non-uniform stress state in a material. For specimens involving non-uniform stress states, such as pre-cracked or notched specimens, there are multi-axial stress states at the crack or notch. As an alternative way to simplify Equation (33) by resorting to the first mean value theorem for integrals, the 'heterogeneity factor' concept as used by Chantier et al. [13] and Pessard, et al. [21] can be also adopted to establish the correlation between the two compound parameters $\frac{1}{V} \ln \left[\frac{1}{(1-P)}\right]$ and $\left(\Delta \sigma_{n o m}\right)^{m} N$. The 'heterogeneity factor' $H_{b}^{*}$ corresponding to 
Equation (33) is written as

$$
H_{b}^{*}=\frac{1}{V} \int_{V}\left[\frac{F\left((\Delta \sigma)^{m} N\right)-a_{i}}{F\left(\left(\Delta \sigma_{n o m}\right)^{m} N\right)-a_{i}}\right]^{b} \frac{\delta V}{V_{0}}
$$

Accordingly, Equation (33) reduces to

$$
P=1-\exp \left\{-H_{b}^{*}\left(\frac{V}{V_{0}}\right)\left[\frac{F\left(\left(\Delta \sigma_{\text {nom }}\right)^{m} N\right)-a_{i}}{a_{0}}\right]^{b}\right\}
$$

Similar to Equation (37), Equation (41) also reveals the existence of the correlation between $\frac{1}{V} \ln \left[\frac{1}{(1-P)}\right]$ and $\left(\Delta \sigma_{\text {nom }}\right)^{m}$ in principle. In practice, the exact values of $\eta_{3}$ in Equation (37) and $H_{b}^{*}$ in Equation (41) depend on the material parameters $\left(a_{i}, b, m\right.$ and $\left.V_{0}\right)$, specimen geometry and the loading mode. The scenarios of pre-cracked and notched specimens will be investigated separately in future.

The models presented above provide a guideline to synchronise the major variables $\left(S=\Delta \sigma_{n o m}, N\right.$ and $V$ ) responsible for fatigue failure. Accordingly, probabilistic modelling of fatigue failure can be conducted with the following steps:

(1). Determine the proper mathematical formulations for cumulative probability of fatigue through synchronising fatigue data analysis by correlating the two compound parameters $\frac{1}{V} \ln \left[\frac{1}{(1-P)}\right]$ and $\left(\Delta \sigma_{n o m}\right)^{m} N$ according to Equation (37), or (39), instead of directly assuming a specific classical empirical distribution function for the cumulative probability, such as a Weibull distribution or logarithmic normal distribution function.

(2). Estimate/calibrate parameters of the established cumulative probability model.

(3). The calibrated model is used for probabilistic modelling of fatigue damage under more complex specimen geometries which involve non-uniform stress distributions according to Equation (33).

In the following, we will evaluate the correlation between the two compound parameters $\frac{1}{V} \ln \left[\frac{1}{(1-P)}\right]$ and $\left(\Delta \sigma_{n o m}\right)^{m} N$ by analysing some published data sets of fatigue failure of specimens subjected to cyclic tension/compression or torsion to validate the extended model Equation (33) and the proposed steps (1) and (2).

\section{Case studies}

In this session, the rank probability $\mathrm{P}$ for the $i$-th specimen is calculated according to $P(i)=(i-0.3) /(n+0.4)$, where $\mathrm{n}$ is the total number of specimens with fatigue life arranged in an ascending order in each group. 


\subsection{Volume effect on fatigue life of equine cortical bone at a fixed loading range}

Bigley et al. [17] investigated the volume effect on fatigue life of equine cortical bone. In their study, three groups of waisted rectangular specimens of cortical bone were isolated from the mid-diaphysis of the dorsal region of equine third metacarpal bones. Each group consists of 6 specimens, all with a nominal cross-section of $3 \times 4 \mathrm{~mm}$. The gauge lengths are $10.5,21$, and $42 \mathrm{~mm}$, respectively, and are along the anatomical long axis of the bone. The corresponding volumes of specimens within the gauge length are 126,252 , and $504 \mathrm{~mm}^{3}$. The exact measurement reported volumes within the gauge length being 118.3 $\pm 11.6(=\mathrm{V} 1), 248.8 \pm 4.9$ (=V2), and $497.5 \pm 7.4 \mathrm{~mm}^{3}(=\mathrm{V} 3)$ for each group, respectively. The specimens were lightly polished with 800-grit carbide paper to remove any surface artefacts from machining. Each specimen was thermally equilibrated for $30 \mathrm{~min}$ and then underwent 100 preconditioning cycles from 10 to $100 \mathrm{~N}$ at $2 \mathrm{~Hz}$. Uniaxial load-controlled fatigue tests were conducted with an initial strain range of $4000 \mu \varepsilon$ (microstrain) under constant irradiation with calcium-buffered saline solution at $37^{\circ} \mathrm{C}$, using a $2 \mathrm{~Hz}$ sinusoidal waveform between $10 \mathrm{~N}$ and a force (exact value not reported) that induces a strain of $4000 \mu \varepsilon$. The number of load cycles to reach complete fracture of the specimen within the waisted gauge length was recorded as the fatigue life, as summarised in Figure 4(a). Two-parameter Weibull statistical analysis of fatigue life for each group led to Weibull modulus of 1.65, 1.62, and 1.43 with the characteristic fatigue life $\mathrm{N}$ (as the scale parameter) of 20055, 16677, and 7927 cycles for 10.5, 21, and $42 \mathrm{~mm}$ long specimens, respectively.

Since the fatigue tests were run with a prismatic beam type specimen in uniaxial cyclic tension at constant values of the minimum stress $\left(\sigma_{\min }\right)$ and the maximum stress $\left(\sigma_{\max }\right), \Delta \sigma_{\text {nom }}=$ const, Equation (39) applies and can be further simplified as (assume $a_{i}=0$ ):

$$
\left\{\frac{1}{V} \ln \left[\frac{1}{(1-P)}\right]\right\}^{1 / b}=\frac{1}{V_{0}^{1 / b}} F\left(N \mid \Delta \sigma_{\text {nоm }}\right)
$$

Equation (42) suggests us to evaluate the correlation between $\frac{1}{V} \ln \left[\frac{1}{(1-P)}\right]$

and $N$. The experimental data in Figure 4(a) are rearranged in Figure 4(b) according to Equation (42). A power-law curve fits all the data well as below.

$$
\frac{1}{V} \ln \left(\frac{1}{1-P}\right)=\frac{N^{b}}{k\left(\Delta \sigma_{n o m} / \sigma_{0}\right) V_{0}}=\left(\frac{N}{580147}\right)^{1.4783}
$$

where $k\left(\Delta \sigma_{\text {nom }} / \sigma_{0}\right)$ denotes a dimensionless coefficient $k$ dependent on nominal stress range $\Delta \sigma_{\text {nom }}$ and scale parameter $\sigma_{0}, \quad b=1.4783$, $\sqrt[b]{k\left(\Delta \sigma_{\text {nom }} / \sigma_{0}\right) V_{0}}=580147(\mathrm{~mm})^{3 / b}$. The coefficient of determination $R^{2}=$ 0.92 was obtained. Note that the compound scale parameter $\sqrt[b]{k\left(\Delta \sigma_{\text {nom }} / \sigma_{0}\right) V_{0}}$ 

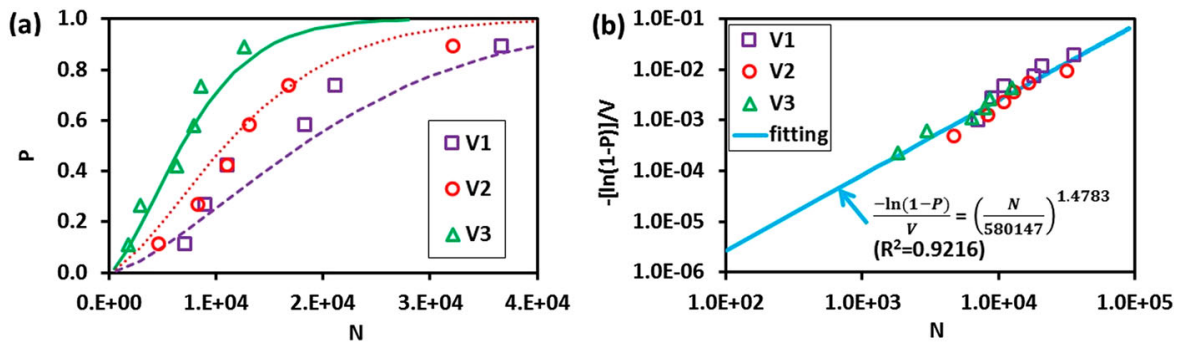

Figure 4. (a) Experimental data of life time $(\mathrm{N})$ for specimens with different volume (V) [17]. The lines are based on Equation (45); (b). Synchronised fatigue data analysis according to Equation (44).

varies with nominal stress range $\Delta \sigma_{\text {nom }}$ instead of being an intrinsic material property.

The lines in Figure 4(a) are based on Equation (43).

\subsection{Probabilistic stress-life analysis of rolling contact fatigue with a fixed specimen volume}

Zhao and Liu [23] studied Weibull modelling of probabilistic stress-life curves for rolling contact fatigue between a circular plate made of a carburisation bearing steel G20CrNi2Mo (serving as bearing raceways) and 16 balls of $5 \mathrm{~mm}$ in radius made of GCr15steel and chained with a plastic cage (serving as bearing rollers). The test bearings were immersed in grease oil. The circular plate rotated at $3000 \mathrm{rpm}$. The recorded life time corresponds to the occurrence of a shelling piece in a bearing system, which was always found at the subsurface of the bottom circular plate. Four groups of contact fatigue tests were conducted at given nominal Hertz contact stress amplitude $\left(\sigma_{a, n o m}\right)$ of $4900,5500,6100$, and $6700 \mathrm{MPa}$, respectively. Each group includes 14 specimens. The experimental results were summarised in Figure 5(a) and listed in Table A1 in Appendix 1.

It is noted that the rolling contact fatigue test involves complex multiaxial stress states at the contact area. Detailed stress distribution can be obtained by finite element analysis. Within the domain of elastic deformation, the experiment involves a fixed volume (V). Therefore, Equation (37) applies and can be further simplified as below for the combined effect of $\sigma_{a, \text { nom }}$ and $N$.

$$
\begin{aligned}
\ln \left(\frac{1}{1-P}\right) & =\left(\frac{V}{V_{0}}\right)^{1 / b} F\left(N, \sigma_{a, \text { nom }} \mid V\right) \\
& =\left(\frac{V}{V_{0}}\right)^{1 / b}\left[\frac{F\left(\eta_{3}\left(\sigma_{a, \text { nom }}\right)^{m} N\right)-a_{i}}{a_{0}}\right]
\end{aligned}
$$

To apply Equation (44) to synchronise the experimental data in Figure 5(a), the value of $m$ need to be evaluated first. Accordingly, Equation (34) is rewritten as

$$
N=\operatorname{Const}(P \mid V)\left(\sigma_{a, n o m}\right)^{-m}
$$



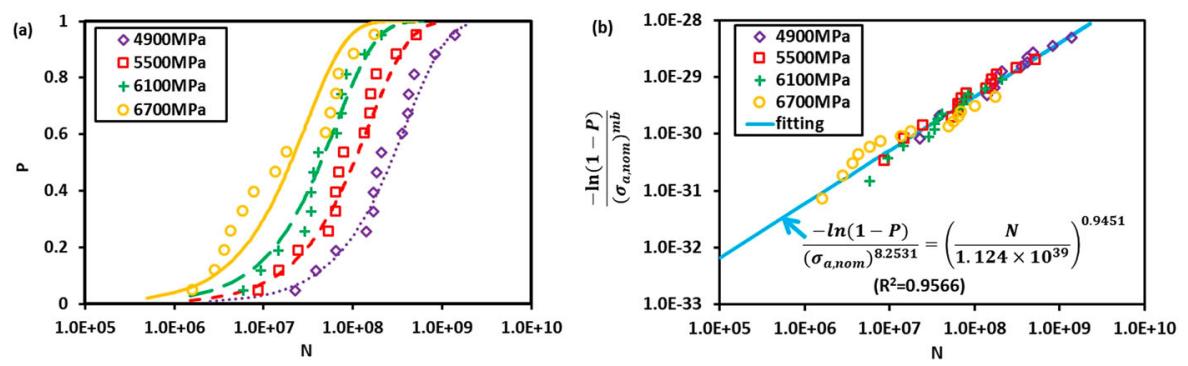

Figure 5. (a) Experimental data of life time $(\mathrm{N})$ distribution at different nominal stress amplitude $\left(\sigma_{a, \text { nom }}\right)[23]$. The lines are based on Equation (48); (b). Synchronised fatigue data analysis according to Equation (46).

At a given value of $P$, a linear regression between $N$ and $\left(\sigma_{a, n o m}\right)^{-m}$ are taken to estimate $m$. The fitting results are summarised in Table 3. Now the experimental data in Figure 5(a) are analysed in Figure 5(b), which fits to the following equation:

$$
\frac{1}{\left(\sigma_{a, n o m}\right)^{m b}} \ln \left(\frac{1}{1-P}\right)=G(N \mid V)=\frac{V}{V_{0}} \frac{1}{\left(\sigma_{0}\right)^{m b}} N^{b}
$$

Equation (46) is equivalent to

$$
\ln \left(\frac{1}{1-P}\right)=\frac{V}{V_{0}}\left[\frac{\left(\sigma_{a, n o m}\right)^{m} N}{\left(\sigma_{0}\right)^{m}}\right]^{b}
$$

or

$$
\begin{aligned}
1-P & =\exp \left\{-\frac{V}{V_{0}}\left[N \cdot\left(\frac{\sigma_{a, \text { nom }}}{\sigma_{0}}\right)^{m}\right]^{b}\right\} \\
& =\exp \left\{-\left[\frac{N \cdot\left(\sigma_{a, n o m}\right)^{m}}{\left(V_{0} / V\right)^{1 / b} \cdot\left(\sigma_{0}\right)^{m}}\right]^{b}\right\}
\end{aligned}
$$

Table 3. Estimated value of $m$ based on Equation (45).

\begin{tabular}{lcccc}
\hline & & \multicolumn{3}{c}{$N=\operatorname{Const}(P, V)\left(\sigma_{a, \text { nom }}\right)^{-m}$} \\
\cline { 2 - 4 } No. & $P$ & $\operatorname{Const}(P, V)$ & $m$ & $R^{2}$ \\
\hline 1 & .049 & $1.94 \mathrm{E}+34$ & 7.3 & .9877 \\
2 & .118 & $1.83 \mathrm{E}+35$ & 7.5 & .9917 \\
3 & .188 & $3.89 \mathrm{E}+36$ & 7.8 & .9933 \\
4 & .257 & $2.59 \mathrm{E}+38$ & 8.2 & .9932 \\
5 & .326 & $3.09 \mathrm{E}+38$ & 8.2 & .9944 \\
6 & .396 & $1.32 \mathrm{E}+38$ & 8.1 & .9960 \\
7 & .465 & $6.14 \mathrm{E}+37$ & 8.0 & .9983 \\
8 & .535 & $2.97 \mathrm{E}+37$ & 7.9 & .9986 \\
9 & .604 & $9.31 \mathrm{E}+36$ & 7.7 & .9926 \\
10 & .674 & $1.64 \mathrm{E}+37$ & 7.8 & .9932 \\
11 & .743 & $4.63 \mathrm{E}+36$ & 7.6 & .9884 \\
12 & .813 & $1.25 \mathrm{E}+37$ & 7.7 & .9912 \\
13 & .882 & $2.74 \mathrm{E}+38$ & 8.0 & .9953 \\
14 & .951 & $1.07 \mathrm{E}+39$ & 8.1 & .9938 \\
\hline
\end{tabular}


with $m=7.8, b=0.9451, \sqrt[b]{\left(V_{0} / V\right)}\left(\sigma_{0}\right)^{m}=1.124 \times 10^{39}\left(\sigma_{0}\right.$ in $\left.\mathrm{MPa}\right)$, the coefficient of determination $R^{2}=0.9566$. Note that the scale parameter $\sqrt[b]{\left(V_{0} / V\right)}\left(\sigma_{0}\right)^{m}$ is volume $(V)$ dependent rather than an intrinsic material parameter.

\subsection{Probabilistic stress-life analysis of torsion fatigue with a fixed specimen volume}

Shimizu et al [4] reported probabilistic stress-life studies on a bearing steel JIS SUJ2/AISI 52100 in alternating torsion life test using 150 cylindrical rod specimens of same size under 6 nominal torsion shear stress amplitudes $\tau_{a, \text { nom }}$ of $0.5,0.63,0.76,0.80,0.95$, and $1.0 \mathrm{GPa}$, which is set on the test rig, with the test speed for varying the stress cycles set from 350 to $960 \mathrm{rpm}$ for high to low stress amplitudes. The corresponding number of specimens at each stress amplitude is $20,19,33,25,25$, and 28 in sequence. The experimental results were summarised in Figure 6(a) and listed in Table A2 in Appendix 1.

It is noted that the alternating torsion fatigue test employs a cylindrical bar of a fixed volume (V). Therefore, Equation (37) applies and can be further simplified as below for the combined effect of $\tau_{a, \text { nom }}$ and $N$.

$$
\begin{aligned}
\ln \left(\frac{1}{1-P}\right) & =\left(\frac{V}{V_{0}}\right)^{1 / b} F\left(N, \tau_{a, \text { nom }} \mid V\right) \\
& =\left(\frac{V}{V_{0}}\right)^{1 / b}\left[\frac{F\left(\eta_{3}\left(\tau_{a, \text { nom }}\right)^{m} N\right)-a_{i}}{a_{0}}\right]
\end{aligned}
$$

Similar to the analysis in Section 4.2 to estimate $m$, the experimental data in Figure 6(a) are synchronised in Figure 6(b), which fits to the following equation:

$$
\frac{1}{\left(\tau_{a, n o m}\right)^{m b}} \ln \left(\frac{1}{1-P}\right)=G(N \mid V)=\frac{V}{V_{0}} \frac{1}{\left(\sigma_{0}\right)^{m b}} N^{b}
$$
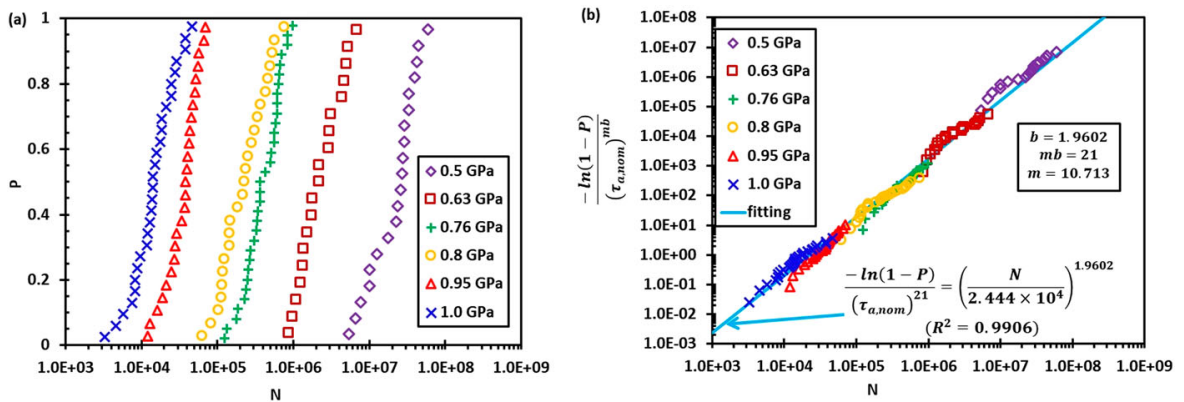

Figure 6. (a). Experimental data of life time $(\mathrm{N})$ distribution at different nominal shear stress amplitude $\left(\tau_{a, \text { nom }}\right)$ [4]. The lines are based on Equation (52); (b). Synchronised fatigue data analysis according to Equation (50). 
Equation (50) is equivalent to

$$
\ln \left(\frac{1}{1-P}\right)=\frac{V}{V_{0}}\left[\frac{\left(\tau_{a, n o m}\right)^{m} N}{\left(\sigma_{0}\right)^{m}}\right]^{b}
$$

or

$$
1-P=\exp \left\{-\frac{V}{V_{0}}\left[N \cdot\left(\frac{\tau_{a, \text { nom }}}{\sigma_{0}}\right)^{m}\right]^{b}\right\}=\exp \left\{-\left[\frac{N \cdot\left(\tau_{a, \text { nom }}\right)^{m}}{\left(V_{0} / V\right)^{1 / b} \cdot\left(\sigma_{0}\right)^{m}}\right]^{b}\right\}
$$

with $m=10.713, b=1.9602, \sqrt[b]{\left(V_{0} / V\right)}\left(\sigma_{0}\right)^{m}=2.444 \times 10^{4}\left(\sigma_{0}\right.$ in $\left.\mathrm{MPa}\right)$, the coefficient of determination $R^{2}=0.9906$. Note that the scale parameter $\sqrt[b]{\left(V_{0} / V\right)}\left(\sigma_{0}\right)^{m}$ is volume $(V)$ dependent rather than an intrinsic material parameter.

\subsection{Combined effect of load amplitude and specimen size on fatigue life of cast iron}

Shirani and Härkegård [20] reported fatigue life of ductile cast iron with graphite nodules distributed on a ferritic matrix, with the fatigue test data being tabulated. Fatigue tests were performed at constant amplitudes per standard ASTM E 466. Two types of different sized cylindrical specimens were adopted: one has a diameter of $21 \mathrm{~mm}$ and a gauge length of $70.59 \mathrm{~mm}$, the other has a diameter of $50 \mathrm{~mm}$ and a gauge length of $178 \mathrm{~mm}$. The corresponding specimen volume $(V)$ within the gauge length is $24449.6 \mathrm{~mm}^{3}$ and $349502.2 \mathrm{~mm}^{3}$, respectively. 3D X-ray computed tomographic inspection on one specimen of each type suggested the size of preexisting defects (e.g. micro-shrinkages) is below $0.2 \mathrm{~mm} .12$ specimens of each type were tested at load ratio $R=-1$. The load frequency was $10 \mathrm{~Hz}$ for $21 \times 70.59(\mathrm{~mm})$ specimens and $1 \mathrm{~Hz}$ for $50 \times 178(\mathrm{~mm})$ specimens. The fatigue test data are given in Figure 7(a) and in Table A3 (Appendix 1). In addition, 12 specimens of $21 \mathrm{~mm}$ diameter were also tested at $R=0$ to study the mean stress effect, which is not included in this study. The experimental result in Figure 7(a) is synchronised in Figure 7(b). For reasonable estimate of rank probability dictated by the total number (n) of specimens, the fatigue test data for broken samples are analysed in this study only for the case of at least three $(n \geq 3)$ specimens at a given stress amplitude. This includes all the 12 sets of data for $50 \times 178(\mathrm{~mm})$ specimens but only 7 sets of data for $21 \times$ $70.59(\mathrm{~mm})$ specimens (3 specimens at $260 \mathrm{MPa}, 4$ specimens $200 \mathrm{MPa}$, the run-out specimen is only counted for the total number of specimen in calculating ranking probability of broken specimens). The following formulation is adopted for the analysis.

$$
\frac{1}{V\left(\sigma_{a, n o m}\right)^{m b}} \ln \left(\frac{1}{1-P}\right)=G(N)=\frac{1}{V_{0}\left(\sigma_{0}\right)^{m b}} N^{b}
$$



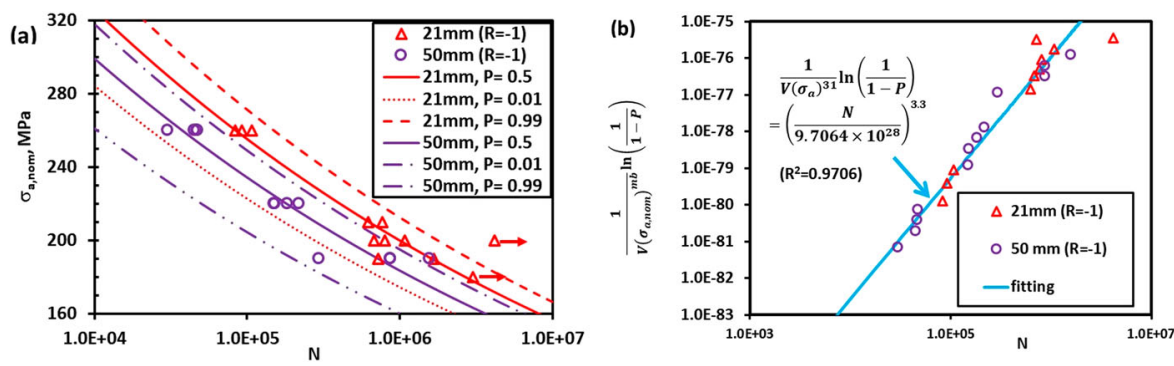

Figure 7. (a). Experimental data of life time $(\mathrm{N})$ distribution at different nominal stress amplitude $\left(\sigma_{a, \text { nom }}\right)$ at $R=-1$ [20]. The lines are based on Equation (55); (b). Synchronised fatigue data analysis according to Equation (53).

Equation (53) can be rewritten as

$$
\ln \left(\frac{1}{1-P}\right)=\frac{V}{V_{0}}\left[\frac{\left(\sigma_{a, n o m}\right)^{m} N}{\left(\sigma_{0}\right)^{m}}\right]^{b}=V\left[\frac{\left(\sigma_{a, n o m}\right)^{m} N}{\sqrt[b]{V_{0}}\left(\sigma_{0}\right)^{m}}\right]^{b}
$$

Or

$$
1-P=\exp \left\{-\frac{V}{V_{0}}\left[N \cdot\left(\frac{\sigma_{a, n o m}}{\sigma_{0}}\right)^{m}\right]^{b}\right\}=\exp \left\{-\frac{V \cdot\left[N \cdot\left(\sigma_{a, n o m}\right)^{m}\right]^{b}}{V_{0} \cdot\left[\left(\sigma_{0}\right)^{m}\right]^{b}}\right\}
$$

with $m_{0}=m b=31, b=3.3, m=m_{0} / b=9.4, \sqrt[b]{V_{0}}\left(\sigma_{0}\right)^{m}=9.706 \times 10^{28}$ $\left(\sigma_{0}\right.$ in $\mathrm{MPa}, V_{0}$ in $\left.\mathrm{mm}^{3}\right)$. Note that the scale parameter $\sqrt[b]{V_{0}}\left(\sigma_{0}\right)^{m}$ is independent of specimen size so it is an intrinsic material property that justifies size scaling of fatigue life.

The stress $\left(\sigma_{a}\right)$ - life $(N)$ fields at cumulative probability of failure $P=0.01$, 0.5, 0.99 are plotted in Figure 7 (a) for the two types of specimens according to Equation (54) to compare with experimental data.

\section{Discussions}

The objective of this work is to develop a statistical model to address the combined effect of specimen size, applied stress amplitude and loading cycles on fatigue failure. While a variety of intrinsic and extrinsic factors can have an influence on a statistical model, it is often impossible and unnecessary to take all the factors into account at once. For example, microcrack interaction is an intrinsic factor for fatigue damage. It is commonly accepted that both coalescence and bifurcation of microcracks can occur during microcrack propagation. However, within the framework of weakest link theory, which presumes the mutual independence of microcracks, the interactions of microcracks must be ignored. As another example, the calibration methods and effect of sample number on the confidence interval of model parameters are 
an important subject for the application of any statistical model, rather than a unique extrinsic factor to a statistical fatigue model. Since this work is focused on establishing a physical connection of specimen size, applied stress amplitude and loading cycles for fatigue failure, the confidence interval of the calibrated parameters is not covered. While the calibration of model parameters such as $b$ and $m$ needs to be optimised to improve model prediction accuracy, the case studies reported above convincingly support a physical correlation between the two compound parameters $\frac{1}{V} \ln \left[\frac{1}{(1-P)}\right]$ and $\left(\Delta \sigma_{n o m}\right)^{m} N$, which is suggested by the new statistical model. During the development of the preceding statistical model of fatigue failure, we have paid significant attentions to the balance between capturing the critical physical understandings of the relevant fatigue mechanisms and achieving rigorous but also simplified mathematical treatments. These efforts are pursued from several aspects as follows. We will also dissect the work of Chantier, et al. [13] as an example to emphasise the necessity of a rigorous mathematical deduction in drawing reliable conclusions.

\subsection{Multiaxial stress states}

Multiaxial stress states commonly exist in real structural components and applications such as rolling element bearings [4, 23] and suspension arms commonly used in vehicles [13]. A multi-axial stress based microscopic fracture criterion is preferred, wmahich can be conceptually expressed as

$$
\sigma_{e}=\sigma_{e}\left(\sigma_{1}, \sigma_{2}, \sigma_{3},\right)=\sigma_{1} \cdot \widetilde{\sigma}_{e}\left(\frac{\sigma_{2}}{\sigma_{1}}, \frac{\sigma_{3}}{\sigma_{1}},\right) \geq s \quad\left(\sigma_{1} \geq \sigma_{2} \geq \sigma_{3}\right)
$$

where $\sigma_{1}, \sigma_{2}$, and $\sigma_{3}$ are the principal stress components acting on a microcrack, $\Omega$ is the solid angle for microcrack orientation, $s$ is the microscopic strength, $\widetilde{\sigma}_{e}$ is the dimensionless expression of the effective stress $\sigma_{e}$ normalised by the maximum principal stress $\sigma_{1}$. A summary of major microscopic fracture criteria is made in [8]. For example, the normal stress component acting on a microcrack plane is adopted as the effective stress $\sigma_{e}$ in [21] for statistical modelling of fatigue behaviour of a forged steel. As shown in Equation (56), the inclusion of the solid angle $\Omega$, in the expression of effective stress $\sigma_{e}$ implies that the statistical distribution of the solid angle $\Omega$ is needed to derive the fracture probability of an individual microcrack $p\left(\sigma, a, V_{0}\right)$ according to Equation (18). So far, most studies assume a uniform distribution of the solid angle $\Omega$ over the full range of $4 \pi$, i.e. the spatial orientation of a microcrack takes a uniform distribution. Note that this adds onto the assumption that all microcracks are penny shaped. Under the very assumption of a uniform distribution of microcrack orientation, a closed-form solution to the 
fracture probability term $F\left(\sigma_{e} \geq s\right)$ in Equation (18) is obtained for a microcrack subjected to multiaxial stresses under the normal tensile stress criterion in [40]. The uniform distribution of microcrack orientation permits to rewrite Equation (18) as below [8,40]:

$$
p\left(\sigma, a, V_{0}\right)=\frac{1}{4 \pi} \int_{\Omega^{*}}\left[\int_{\sigma_{t h}}^{\sigma_{e}} g(s) \cdot \mathrm{d} s\right] d=\frac{1}{4 \pi} \int_{\Omega^{*}}\left[\int_{a\left(\sigma_{e}\right)}^{a\left(\sigma_{t h}\right)} f(a) \cdot \mathrm{d} a\right] d
$$

where $\Omega^{*}$ is the solid angle within which $\sigma_{e} \geq \sigma_{t h}$.

According to expression (56), substituting $\sigma_{e}=\sigma_{1} \cdot \widetilde{\sigma}_{e}\left(\frac{\sigma_{2}}{\sigma_{1}}, \frac{\sigma_{3}}{\sigma_{1}},\right)$ in Equation (57) leads to the formulation of $p\left(\sigma, a, V_{0}\right)$ in terms of the maximum principal stress $\sigma_{1}$, while the effect of stress state will be embodied in the integral involving $\widetilde{\sigma}_{e}$ and finally reflected by the 'heterogeneity factor' $H_{b}^{*}$ as in Equation (40) for the formulation of the cumulative failure probability $\mathrm{P}$, as shown in [21]. This justifies the adoption of nominal stress in a statistical model to characterise the rolling contact fatigue in Section 4.2 of this study and the biaxial in-plane fatigue failure of a suspension arm in [13]. However, the adoption of $\sigma_{1}$ instead of $\sigma_{e}$ is valid only for specimens of self-similar geometry but different sizes since the contribution of the normalised stress term $\widetilde{\sigma}_{e}\left(\frac{\sigma_{2}}{\sigma_{1}}, \frac{\sigma_{3}}{\sigma_{1}},\right)$ stays the same for geometrically self-similar specimens. Particularly, $\sigma_{e}=\sigma_{1}$ leads to $\widetilde{\sigma}_{e}=1$. So we expect that the influence of different definitions of $\sigma_{e}$ for multiaxial stress conditions will have an effect on the value of the heterogeneity factor' $H_{b}^{*}$ as in Equation (40), but not on the shape factors of a statistical distribution function such as Weibull modulus $m$ and $b$. This is supported by the synchronisation of fatigue data from geometrically self-similar but different sized specimens in this study in Section 4. When specimen geometry and loading mode change, the contribution of $\widetilde{\sigma}_{e}\left(\frac{\sigma_{2}}{\sigma_{1}}, \frac{\sigma_{3}}{\sigma_{1}},\right)$ to the 'heterogeneity factor' $H_{b}^{*}$ will change. Therefore, the transferability of fatigue data between specimens of different geometries or loading modes needs to be addressed in future study.

\subsection{Statistical distribution function of instant microcrack size a}

It is of critical importance to select a statistical distribution function of instant microcrack size a. The work adopts Weibull PDF as in Equation (22) to describe the size distribution of microcracks due to its great flexibility to characterise different shaped distributions as illustrated in Figure 3. It leads to the much simple expressions of $p\left(\sigma, a, V_{0}\right)$ for an individual microcrack in Equation (23) and the cumulative probability $\mathrm{P}$ in Equations (24) and (25). As shown in Section 4, this permits to conduct correlations of fatigue parameters and calibrate the model parameters using fatigue experiments. In comparison, Yaacoub Agha, et al. [41] adopted a beta function as below for the flaw size distribution in 
a spheroidal graphite cast iron:

$$
f(a)=\frac{a^{\alpha-1}\left(a_{\max }-a\right)^{\beta-1}}{B_{\alpha \beta} a_{\max }^{\alpha+\beta-1}} \quad\left(0<a<a_{\max }, \alpha, \beta>0\right)
$$

where $B_{\alpha \beta}$ is the beta function, $\alpha=2.3, \beta=18, a_{\max }=400 \mu \mathrm{m}$ were determined from experiments.

Substitution of Equation (58) in Equation (20) leads to an implicit formulation of $p\left(\Delta \sigma, a, V_{0}\right)$ that consists of the regularised incomplete beta function. Substitution of $p\left(\Delta \sigma, a, V_{0}\right)$ in Equation (15) or (17) results in a much more complicated, implicit expression of the cumulative failure probability $\mathrm{P}$. In the case that the model parameters $\alpha, \beta$, and $a_{\max }$ are not directly measureable, it will be much difficult to calibrate these model parameters according to the implicit expression of the cumulative failure probability $\mathrm{P}$ with fatigue experiments. It is also unnecessary to adopt the beta function in Equation (58) to describe the flaw size distribution. As shown in Figure 8, the beta function with $\alpha=2.3, \beta=18, a_{\max }=400 \mu \mathrm{m}$ can be closely approximated by the easy-to-handle Weibull PDF in Equation (22) with $a_{i}=0, a_{0}=49 \mathrm{~m}, b=1.76$.

As a continuation of the work in [41], Chantier, et al. [13] developed a statistical model of fatigue of the same steel. Unfortunately, the work of Chantier, et al. [13] mistakenly expressed the beta function for the flaw size distribution in Equation (58) as the following:

$$
f(a)=\frac{a^{\alpha}\left(a_{\max }-a\right)^{\beta}}{B_{\alpha \beta} a_{\max }^{\alpha+\beta+1}} \quad\left(0<a<a_{\max }, \alpha, \beta>0\right)
$$

with the same values of $\alpha=2.3, \beta=18, a_{\max }=400 \mu \mathrm{m}$. Note the difference in the powers of $a,\left(a_{\max }-a\right)$, and $a_{\max }$ in Equations (58) and (59). In the same work of [13], Equation (59) was then approximated by the following expression to obtain explicit formulation of $p\left(\sigma, a, V_{0}\right)$ for an individual microcrack in Equation (20) and the cumulative probability $\mathrm{P}$ to highlight the effect of 'stress heterogeneity factor':

$$
f(a) \cong \frac{W\left(a_{\max }-a\right)^{\beta}}{a_{\max }^{\beta+1}} \quad\left(0<a<a_{\max }, \beta>0\right)
$$

where $W$ is a coefficient.

The adoption of Equation (60) suggests that the wrong expression of the beta distribution in Equation (59) was more likely taken during the model development phase rather than in the typesetting process of the manuscript.

The wrong expression of $f(a)$ in Equation (59) does not satisfy the normalisation condition in Equation (21). As shown in Figure 8, the value of $f(a)$ in Equation (59) is much smaller than that of the correct formulation in Equation (58), leading to a much lower value of $p\left(\Delta \sigma, a, V_{0}\right)$ than its real value according 


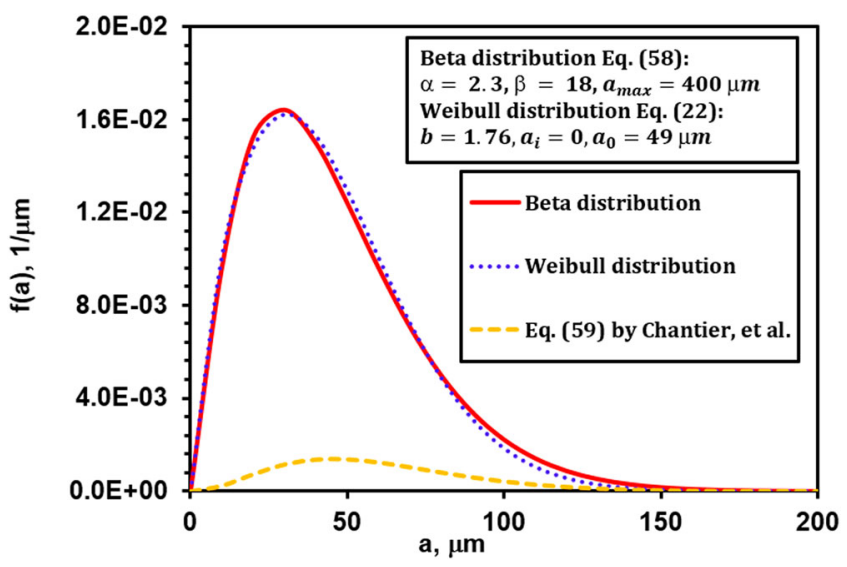

Figure 8. Approximate representation of a beta distribution by a Weibull distribution, and a comparison of the wrong and correct expressions of beta distribution.

to Equation (20). This may well interpret why the predicted cumulative probability for fatigue failure is much lower than the experimental results at a given loading condition (load amplitude and number of load cycles) as reported in Figure 4 in the work of [13].

Chantier, et al. [13] further derived the expressions of $p\left(\Delta \sigma, a, V_{0}\right)$ for an individual microcrack as below:

$$
p\left(\Delta \sigma, a, V_{0}\right)=\frac{W}{(\beta+1)}\left[1-\left(\frac{\sigma_{t h}}{\sigma_{1}}\right)^{\beta+1}\right]
$$

Equation (61) was further approximated to the following for $\sigma_{1} \rightarrow \sigma_{t h}$ :

$$
p\left(\Delta \sigma, a, V_{0}\right)=\left[\left(\frac{\sigma_{1}-\sigma_{t h}}{\sigma_{0}}\right)^{\beta+1}\right]
$$

With

$$
\sigma_{0}=\frac{\sigma_{\text {th }}}{2}\left(\frac{W}{\beta+1}\right)^{1 /(\beta+1)}
$$

Finally, the following expression for the cumulative probability $\mathrm{P}$ of fatigue failure was achieved in [13]:

$$
P=1-\exp \left[-\frac{H_{\beta+1}^{*} V}{V_{0}}\left(\frac{\sigma_{n o m}-\sigma_{t h}}{\sigma_{0}}\right)^{\beta+1}\right]
$$

Refer to [13] for the detailed expression of the 'stress heterogeneity factor' $H_{\beta+1}^{*}$, which characterises the effect of loading manner on failure probability. Note that the formulations of both $p\left(\Delta \sigma, a, V_{0}\right)$ in Equations (61) and (62) and $P$ in Equation (64) do not include the number of loading cycles $\mathrm{N}$ as a variable, 
unlike Equations (35) and (41) in the new model. This will be further analysed in Section 5.3 .

The reader is cautioned that even if Equation (60) were correct, the resultant formulations Equations (61)-(64) are wrong. In fact, applying the normalisation condition Equation (21) with $a_{i}=0$ to $f(a)$ in Equation (60) results in the solution to $W$ :

$$
\int_{0}^{a_{\max }} \frac{W\left(a_{\max }-a\right)^{\beta}}{a_{\max }^{\beta+1}} \mathrm{~d} a=1 \quad W=\beta+1
$$

Equation (60) thus reduces to

$$
f(a) \cong \frac{\left(a_{\max }-a\right)^{\beta}}{(\beta+1) a_{\max }^{\beta+1}} \quad\left(0<a<a_{\max }, \beta>0\right)
$$

Substitution of Equation (66) in Equation (20) yields

$$
p\left(\Delta \sigma, a, V_{0}\right)=\int_{a}^{a_{\max }} \frac{\left(a_{\max }-a\right)^{\beta}}{(\beta+1) a_{\max }^{\beta+1}} \mathrm{~d} a=\left(1-\frac{a}{a_{\max }}\right)^{\beta+1}
$$

Due to the Griffith law, $\sigma_{1} \sqrt{a}=$ Const, Equation (67) is rewritten as:

$$
p\left(\Delta \sigma, a, V_{0}\right)=\left[1-\left(\frac{\sigma_{t h}}{\sigma_{1}}\right)^{2}\right]^{\beta+1}
$$

Obviously, Equation (68) is different from Equation (61) and by no means can it be rewritten as Equation (62).

\subsection{Growth rate of a microcrack under cyclic loading}

Similar to the case of macrocracks, the growth rate $\mathrm{d} a / \mathrm{d} N$ of microcracks is also generally described as a function of the range of stress intensity factor $\Delta K$ as in Equation (26). Both the conventional Paris' law in Equation (29) and various modified versions of Paris' law are suggested to model the growth rate of a microcrack. Take the VHCF behaviour of metallic materials for example. The formation of the Fine Granular Area (FGA) or Optically Dark Area (ODA) consumes more than $95 \%$ of the VHCF life time $[5,6,43,44]$. As summarised by Paolino et al. [44], a three-stage process is often used to describe a VHCF failure from an internal microdefect within the FGA:

Stage I. the growth phase of an initial defect within the FGA, with $n_{I}$ being the number of cycles consumed. The following modified Paris' law is used to model the defect growth rate:

$$
\frac{\mathrm{d} a}{\mathrm{dN}}=c_{I}\left(K_{I}-K_{t h, L}\right)^{m_{I}}
$$


where $c_{I}$ and $m_{I}$ are the Paris' constants, $K_{t h, L}$ is the local threshold of stress intensity factor.

Stage II. The steady growth phase of the defect from the border of FGA up to the border of the fish-eye, with $n_{I I}$ being the number of cycles consumed;

Stage III. The unsteady growth phase of the defect beyond the fish-eye border, with $n_{I I I}$ as the number of cycles consumed.

In both stages II and III, the growth rate of a defect is modelled by the conventional Paris' law but with different Paris' parameters $\left(c_{I I}\right.$ and $m_{I I}$ for stage II; $c_{I I I}$ and $m_{I I I}$ for stage III).

By properly partitioning the total number of cycles to failure into $n_{I}, n_{I I}$, and $n_{I I I}$, all the Paris' parameters in each phase can be estimated.

In the current work, the conventional Paris law in Equation (29) is used to describe the microcrack growth law. As shown in Equation (32a,b), it reveals the instant microcrack size $a$ to be an explicit function of the compound parameter $(\Delta \sigma)^{m} N$, i.e. $a=F\left((\Delta \sigma)^{m} N\right)$, which guides us to finally reach Equations (37) and (41) that rationalise the physical correlation between the two compound parameters $\frac{1}{V} \ln \left[\frac{1}{(1-P)}\right]$ and $\left(\Delta \sigma_{n o m}\right)^{m} N$.

Yaacoub Agha, et al. [41] and then Chantier, et al. [13] adopted the following modified Paris' law by Pellas et al. [45] for the microcrack growth rate in a same spheroidal graphite cast iron to develop a statistical model of fatigue failure:

$$
\frac{\mathrm{d} a}{\mathrm{~d} N}=c_{0}\left(\Delta K_{e f f}\right)^{m}, \quad \Delta K_{e f f}=\left[K_{\max } g(R)-K_{t h}\right] /\left[K_{c}-K_{t h} / g(R)\right]
$$

where $g(R)$ is a function of the load ratio $R, K_{c}$ is the critical stress intensity factor for local failure.

Integration of Equation (70) gives the closed-form solution as follows:

$$
\varphi\left(\sqrt{\frac{a}{a_{\max }}}\right)-\varphi\left(\sqrt{\frac{a_{i}}{a_{\max }}}\right)=\frac{c_{0}}{a_{\max }}\left[\frac{g(R) K_{t h}}{K_{c}-K_{t h} / g(R)}\right]^{m}\left(\frac{\sigma_{\max }}{\sigma_{t h}}\right)^{m} N
$$

However, the expression of function $\varphi(x)$ depends on the power $m$ as follows:

$$
\varphi(x)=\left\{\begin{array}{cc}
2\left[x+x_{t h} \ln \left(x-x_{t h}\right)\right] & (m=1) \\
2 \ln \left(x-x_{t h}\right)-\frac{2 x}{\left(x-x_{t h}\right)} & (m=2) \\
\frac{2\left[x_{t h}-(m-1) x\right]}{(m-1)(m-2)\left(x-x_{t h}\right)^{m-1}} & (m \neq 1,2)
\end{array} \quad\left(x_{t h}=\frac{\sigma_{t h}}{\sigma_{\max } g(R)}\right)\right.
$$

This raises two difficult issues: First, it is unclear how to determine the value of $m$ for microcrack growth; Second, by integration of the microcrack growth rate model, it is supposed to formulate the instant microcrack size $a$ as a function of stress amplitude $\Delta \sigma$ and number of load cycles $N$, as we demonstrated in the newly developed model in Section 3. However, due to the complexities of the expressions of function $\varphi(x)$, an explicit expression of $a$ as a function of $\Delta \sigma$ 
and $N$ similar to Equation (32 a,b) is not possible. This eventually prevents us to gain a clear physical correlation of the cumulative failure probability $P$ with specimen size $V$, load amplitude $\Delta \sigma$ and number of load cycles $N$, such as correlation between the two compound parameters $\frac{1}{V} \ln \left[\frac{1}{(1-P)}\right]$ and $\left(\Delta \sigma_{\text {nom }}\right)^{m} N$ drawn from the newly developed model. This is the reason for Chantier, et al. [13] to rely on Equation (64) in Section 5.2 to explain the stress heterogeneity effect.

\section{Summary and conclusions}

Based on a Weibull size distribution and a uniform spatial distribution of microcracks, a weakest-link probabilistic model Equation (33) for cyclic stress induced fatigue failure is developed. The model incorporates the combined effect of geometrical size, stress range and number of load cycles to the occurrence of fatigue failure. The model provides a methodology to correlate the experimental data for a combined effect of the three key variables as guidance to formulate an explicit cumulative probability model.

(1). The model suggests that the effect of stress range and number of load cycles can be collectively represented by the compound parameter $\left(\Delta \sigma_{n o m}\right)^{m} N$, which is reminiscent of the empirical formulae of $S-N$ curve. Alternatively, according to the model, the empirical $S-N$ formulae can be justified by the growth behaviour of microcracks during cyclic loading.

(2). The model is validated by four sets of published fatigue test data for the combined effect of volume and number of load cycles for a given stress amplitude, stress amplitude and number of load cycles for a given volume, and all the three parameters of volume, number of load cycles, and stress amplitude, respectively.

(3). As revealed by comparing the four examples, an intrinsic scale parameter for the cumulative probability model can be obtained only when all the three variables are counted in. When the cumulative probability is taken as a two dimensional function of $V$ and $N$ (as in the first example) or $\Delta \sigma_{n o m}$ and $N$ (as in the second example), the resultant scale parameter is not intrinsic but dependent on the third variable ( $\Delta \sigma_{n o m}$ for the first example and $\mathrm{V}$ for the second), thus limiting the scalability of the one- or two-dimensional models.

It is noted that current studies are limited to different sized specimens of similar geometry under same loading mode. Future studies will expand to specimens of different geometries and/or different loading modes.

\section{Acknowledgements}

Wei-Sheng Lei is indebted to Professors Winfried Dahl and Wolfgang Bleck for hosting an earlier research stay at the Institute of Ferrous Metallurgy (IEHK), RWTH Acchen Technical University under the Alexander von Humboldt Research Fellowship. 


\section{Disclosure statement}

No potential conflict of interest was reported by the authors.

\section{Funding}

The financial support of the National Natural Science funding (No. 11872364) and CAS Pioneer Hundred Talents Program is acknowledged.

\section{Nomenclature}

$\begin{array}{ll}a & \text { microcrack size } \\ a_{i} & \text { initial microcrack size } \\ a_{\max } & \text { maximum microcrack size } \\ \mathrm{A}, \mathrm{L}, \mathrm{V} & \text { specimen surface area, length and volume in sequence } \\ A_{0}, L_{0}, V_{0} & \text { reference area, length and volume in sequence } \\ E & \text { elastic modulus } \\ F\left(\sigma_{e} \geq s\right) & \text { fracture probability of an existing microcrack } \\ K_{I} & \text { mode-I stress intensity factor } \\ \Delta K & \text { range of stress intensity factor } \\ K_{\max }, K_{\min } & \text { maximum and minimum stress intensity factors } \\ K_{c} & \text { critical stress intensity factor for local failure } \\ K_{t h, L} & \text { local threshold of stress intensity factor } \\ N & \text { number of loading cycles } \\ n^{\prime} & \text { cyclic strain-hardening exponent } \\ P & \text { cumulative probability } \\ p\left(\sigma, a, V_{0}\right) & \text { fracture probability of volume element } V_{0} \text { with a microcrack } \\ R & \text { stress ratio } \\ S & \text { generalised cyclic load } \\ \bar{S} & \text { average value of } S \text { on all the possible material planes } \\ s & \text { microscopic fracture strength } \\ \sigma_{y s} & \text { yield stress } \\ \sigma_{1}, \sigma_{2}, \sigma_{3} & \text { principal stresses } \\ \sigma_{i j}(t) & \text { instant stress component at time } t \\ \sigma_{e}, \Delta \sigma_{e} & \text { effective stress and its range } \\ \sigma_{m} & \text { mean stress } \\ \sigma_{n} & \text { normal stress component } \\ \Delta \sigma, \Delta \sigma_{\text {nom }} & \text { local and nominal stress ranges } \\ \sigma_{\max }, \sigma_{\min } & \text { maximum and minimum stresses } \\ \sigma_{a}, \sigma_{a, n o m} & \text { local and nominal tensile stress amplitudes } \\ \tau_{a}, \tau_{a, n o m} & \text { local and nominal shear stress amplitudes } \\ \dot{\varepsilon}_{i j}(t) & \text { instant strain rate at time } t \\ \varepsilon_{\max }, \varepsilon_{\min } & \text { maximum and minimum strains } \\ \Delta \varepsilon, \Delta \Delta \varepsilon_{\text {nom }} & \text { local and nominal strain ranges } \\ \varepsilon_{a}, \varepsilon_{a, n o m} & \text { local and nominal strain amplitudes } \\ \varepsilon_{p, a}, \Delta \varepsilon_{p} & \text { plastic strain amplitude and plastic strain range } \\ \Delta \gamma & \text { shear strain range } \\ \varepsilon_{f}^{\prime} & \text { fatigue ductility coefficient } \\ \Delta W_{t} & \\ & \end{array}$




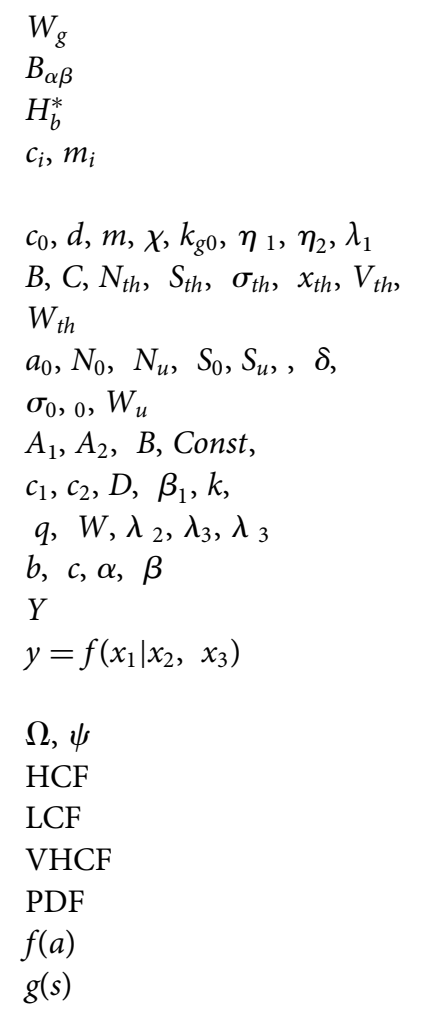

strain work density per loading cycle with the period $T$ beta function stress heterogeneity factor model parameters in Paris' law for microcracks $(i=I, I I, I I I)$

material constant

thresholds

scale parameters

constants

shape factors

dimensionless parameter dependent on crack geometry

$y$ as a function of variable $x_{1}$ with given values of variables $x_{2}$ and $x_{3}$

angles

high cycle fatigue

low cycle fatigue

very high cycle fatigue

probability density function

PDF of microcrack size $(a)$

PDF of microscopic fracture strength $(s)$

\section{References}

[1] W.-S. Lei, A framework for statistical modelling of plastic yielding initiated cleavage fracture of structural steels, Philos. Mag. 96 (2016), pp. 3586-3631.

[2] W.-S. Lei, A generalized weakest-link model for size effect on strength of quasi-brittle materials. J. Mater. Sci 53 (2018), pp. 1227-1245.

[3] G. Qian, W.-S. Lei, M. Niffenegger and V.F. González-Albuixech, On the temperature independence of statistical model parameters for cleavage fracture in ferritic steels. Philos. Mag 98 (2018), pp. 959-1004.

[4] S. Shimizu, K. Tsuchiya and K. Tosha, Probabilistic stress-life (P-S-N) study on bearing steel using alternating torsion life test. Tribology Trans 52 (2009), pp. 807-816. doi:10. 1080/10402000903125345.

[5] Y. Hong and C. Sun, The nature and the mechanism of crack initiation and early growth for very-high-cycle fatigue of metallic materials - an overview. Theor. Appl. Fract. Mech 92 (2017), pp. 331-350.

[6] G. Qian, C. Zhou and Y. Hong, Experimental and theoretical investigation of environmental media on very-high-cycle fatigue behavior for a structural steel. Acta Mater 59 (2011), pp. 1321-1327.

[7] A. Pineau, Development of the local approach to fracture over the past 25 years: theory and applications. Int. J. Fract 138 (2006), pp. 139-166.

[8] W.-S. Lei, A cumulative failure probability model for cleavage fracture in ferritic steels. Mech. Mater 93 (2016), pp. 184-198.

[9] W.-S. Lei, On the statistical modeling of cleavage fracture toughness of structural steels. Mech. Mater 101 (2016), pp. 81-92. 
[10] G. Qian, Y. Cao, M. Niffenegger, Y. Chao and W. Wu, Comparison of constraint analyses with global and local approaches under uniaxial and biaxial loadings. Eur. J. Mech. / A Solids 69 (2018), pp. 135-146.

[11] F.A. Bastenaire, New method for the statistical evaluation of constant stress amplitude fatigue-test results. Probabilistic aspects of fatigue. ASTM STP 511. ASTM, 1972, 3-28.

[12] G. Schweiger and K. Heckel, Size effect in randomly loaded specimens. Int. J. Fatigue 8 (1986), pp. 231-234.

[13] I. Chantier, V. Bobet, R. Billardon and F. Hild, A probabilistic approach to predict the very high-cycle fatigue behavior of spherical graphite cast iron structures. Fatigue Fract. Engng. Mater. Struct 23 (2000), pp. 173-180.

[14] J. Schijve, Statistical distribution of functions and fatigue of structures. Int. J. Fatigue 27 (2005), pp. 1031-1039.

[15] T. Delahay and T. Palin-Luc, Estimation of the fatigue strength distribution in high-cycle multiaxial fatigue taking into account the stress-strain gradient effect. Int. J. Fatigue 28 (2006), pp. 474-484.

[16] E. Castillo, M. Lopez-Aenlle, A. Rambo, A. Fernandez-Canteli, R. Kieselbach and V. Esslinger, Specimen length effect on parameter estimation in modeling fatigue strength by Weibull distribution. Int. J. Fatigue 28 (2006), pp. 1047-1058.

[17] G. Bigley R. F., J.C. Stover, S.M. Hazelwood, S.J. Fyhrie, D.P. Martin and R. B, Volume effects on fatigue life of equine cortical bone. J. Biomech 40 (2007), pp. 3548-3554.

[18] A. Karolczuk, The probabilistic model of fatigue life estimation for structural elements with heterogeneous stress distribution, The Arch. Mech. Eng. LV(3) (2008), pp. 213-225.

[19] E. Castillo, A. Fernandez-Canteli, R. Koller, M.L. Ruiz-Ripoll and A. Garcia, A statistical fatigue model covering the tension and compression Wohler fields. Probabilistic Eng. Mech 24 (2009), pp. 199-209.

[20] M. Shirani and G. Harkegard, Fatigue life distribution and size effect in ductile cast iron for wind turbine components. Eng. Failure Analysis 18 (2011), pp. 12-24.

[21] E. Pessard, F. Morel, A. Morel and D. Bellett, Modeling the role of non-metallic inclusions on the anisotropic fatigue behavior of forged steel. Int. J. Fatigue 33 (2011), pp. 568-577.

[22] O.A. Okeyoyin and G.M. Owolabi, Application of weakest link probabilistic framework for fatigue notch factor to turbine engine materials. World J. Mech 3 (2013), pp. 237-244.

[23] Y.X. Zhao and H.B. Liu, Weibull modeling of the probabilistic S-N curves for rolling contact fatigue. Int. J. Fatigue 66 (2014), pp. 47-54.

[24] D. Sandberg and M. Olsson, An investigation of the prediction accuracy for volume based HF models using scaled geometries and scaled loading. Int. J. Fatigue 82 (2016), pp. 317-324.

[25] J. Correia, N. Apetre, A. Arcari, A. De Jesus, M. Muniz-Calvente, R. Calcada, F. Berto and A. Fernandez-Canteli, Generalized probabilistic model allowing for various fatigue damage variables. Int. J. Fatigue 100 (2017), pp. 187-194.

[26] A. Wöhler, Über die Festigkeits-Versuche mit Eisen und Stahl (On strength tests of iron and steel). Zeitschrift für Bauwesen 20 (1870), pp. 73-106.

[27] O.H. Basquin, The exponential law of endurance tests, Proc. ASTM, Vol.10, Part 11, ASTM, East Conshohocken, PA, 1910, pp. 625-630.

[28] C. Stromeyer, The determination of fatigue limits under alternating stress conditions, Proc. Roy. Soc. Lond. 1914; 90(620):411-425.

[29] A. Palmgren, Die Lebensdauer von Kugellagern (The life span of ball bearings). VDIZeitschrift 68 (1924), pp. 339-341.

[30] L.F. Coffin, A study of the effects of cyclic thermal stresses on a ductile metal. Trans. ASME 76(6) (1954), pp. 931-949. 
[31] S.S. Manson, Behavior of materials under conditions of thermal stress, National Advisory Committee for Aeronautics Technical Report (NACA-TR) 1170, 1954.

[32] J. Kohout and S. Vechet, A new function for fatigue curves characterization and its multiple merits. Int. J. Fatigue 23(2) (2001), pp. 175-183.

[33] K.N. Smith, P. Watson and T.H. Topper, A stress-strain function for the fatigue of metals. J. Mater 5(4) (1970), pp. 767-778.

[34] Walker, K., The effect of stress ratio during crack propagation and fatigue for 2024-T3 and 7075-T6 aluminum. In: Effects of environment and complex load history on fatigue life, ASTM STP 462, Philadelphia, PA, 1970, pp. 1-14.

[35] A. Fatemi and D.F. Socie, A critical plane approach to multiaxial fatigue damage including out of plane loading. Fatigue Fract. Eng. Mater. Struct 11 (1988), pp. 149-165.

[36] K. Golos and F. Ellyin, A total strain energy density theory live damage. J. Pressure Vessel Technol. Trans. ASME 110 (1988), pp. 36-41.

[37] W. Weibull, A statistical theory of the strength of materials. Ingeniorsvetenskapaka demiens. Handlinger 151 (1939), pp. 1-45.

[38] W.-S. Lei, Statistical size scaling of ceramic strength. J. Am. Ceram. Soc 102 (2019), pp. 90-97.

[39] G. Qian, W.-S. Lei, Z. Yu, and F. Berto, Statistical size scaling of breakage strength of irregularly-shaped particles. Theor. Appl. Fract. Mech 102 (2019), pp. 51-58.

[40] W.-S. Lei, Fracture probability of a randomly oriented microcrack under multi-axial loading for the normal tensile stress criterion. Theor. Appl. Fract. Mech 85 (2016), pp. 164-172.

[41] H. Yaacoub Agha, A.-S. Beranger, R. Billardon, and F. Hild, High-cycle fatigue behavior of spheroidal graphite cast iron, Fatigue Fract. Eng. Mater. Struct. 21 (1998), pp. 287-296

[42] B. Tomkins, Fatigue crack propagation-an analysis. Philos. Mag 155 (1968), pp. 10411066.

[43] Y. Hong, X. Liu, Z. Lei and C. Sun, The formation mechanism of characteristic region at crack initiation for very-high-cycle fatigue of high-strength steels. Int. J. Fatigue 89 (2016), pp. 108-118.

[44] D.S. Palino, A. Tridello, G. Chiandussi and M. Rossetto, Effect of defect size on P-N curves in very-high-cycle fatigue. Procedia Structural Integrity 7 (2017), pp. 335-342.

[45] J. Pellas, G. Baudin, and M. Robert, Mesure et calcul du seuil de fissuration après surcharge. Recherche aérospatiale 3 (1977), pp. 191-201. 


\section{Appendix 1}

Table A1. Rolling contact fatigue test data of bearing steel by Zhao and Liu [23].

\begin{tabular}{lcccc}
\hline & \multicolumn{4}{c}{ Fatigue life $N$ (cycles) } \\
\cline { 2 - 5 } Specimen number & $\sigma_{a}=4900 \mathrm{MPa}$ & $\sigma_{a}=5500 \mathrm{MPa}$ & $\sigma_{a}=6100 \mathrm{MPa}$ & $\sigma_{a}=6700 \mathrm{MPa}$ \\
\hline 1 & $2.25 \mathrm{E}+7$ & $8.77 \mathrm{E}+6$ & $5.88 \mathrm{E}+6$ & $1.63 \mathrm{E}+6$ \\
2 & $3.88 \mathrm{E}+7$ & $1.50 \mathrm{E}+7$ & $9.43 \mathrm{E}+6$ & $2.88 \mathrm{E}+6$ \\
3 & $6.42 \mathrm{E}+7$ & $2.48 \mathrm{E}+7$ & $1.46 \mathrm{E}+7$ & $3.72 \mathrm{E}+6$ \\
4 & $1.41 \mathrm{E}+8$ & $5.40 \mathrm{E}+7$ & $2.90 \mathrm{E}+7$ & $4.38 \mathrm{E}+6$ \\
5 & $1.70 \mathrm{E}+8$ & $6.49 \mathrm{E}+7$ & $3.41 \mathrm{E}+7$ & $5.98 \mathrm{E}+6$ \\
6 & $1.70 \mathrm{E}+8$ & $6.52 \mathrm{E}+7$ & $3.42 \mathrm{E}+7$ & $7.99 \mathrm{E}+6$ \\
7 & $1.85 \mathrm{E}+8$ & $7.07 \mathrm{E}+7$ & $3.67 \mathrm{E}+7$ & $1.39 \mathrm{E}+7$ \\
8 & $2.10 \mathrm{E}+8$ & $8.02 \mathrm{E}+7$ & $4.10 \mathrm{E}+7$ & $1.83 \mathrm{E}+7$ \\
9 & $3.61 \mathrm{E}+8$ & $1.37 \mathrm{E}+8$ & $6.57 \mathrm{E}+7$ & $5.07 \mathrm{E}+7$ \\
10 & $4.16 \mathrm{E}+8$ & $1.58 \mathrm{E}+8$ & $7.42 \mathrm{E}+7$ & $5.73 \mathrm{E}+7$ \\
11 & $4.21 \mathrm{E}+8$ & $1.60 \mathrm{E}+8$ & $7.51 \mathrm{E}+7$ & $6.61 \mathrm{E}+7$ \\
12 & $4.86 \mathrm{E}+8$ & $1.84 \mathrm{E}+8$ & $8.50 \mathrm{E}+7$ & $7.07 \mathrm{E}+7$ \\
13 & $8.29 \mathrm{E}+8$ & $3.12 \mathrm{E}+8$ & $1.35 \mathrm{E}+8$ & $1.03 \mathrm{E}+8$ \\
14 & $1.39 \mathrm{E}+9$ & $5.20 \mathrm{E}+8$ & $2.11 \mathrm{E}+8$ & $1.79 \mathrm{E}+8$ \\
\hline
\end{tabular}

Table A2. Fatigue test data of ductile cast iron at load ratio $R=-1$ by Shirani and Härkegård [20].

\begin{tabular}{lcrl}
\hline Specimen number & Nominal stress amplitude $\left(\sigma_{a, \text { nom }}\right), \mathbf{M P a}$ & Fatigue life $(\mathrm{N})$, cycle & Note \\
\hline $\mathbf{2 1} \times \mathbf{7 0 . 5 9}(\mathbf{m m})$ specimens, $\mathbf{R}=\mathbf{- 1}, \mathbf{V}=\mathbf{2 4 4 4 9 . 6} \mathbf{~ m m}^{\mathbf{3}}$ & & \\
1 & 180 & $3,000,000$ & Runt out \\
2 & 190 & 716,400 & Broken \\
3 & 190 & $1,674,100$ & Broken \\
4 & 200 & 679,400 & Broken \\
5 & 200 & 801,000 & Broken \\
6 & 200 & $1,076,600$ & Broken \\
7 & 200 & $4,181,701$ & Runt out \\
8 & 210 & 619,200 & Broken \\
9 & 210 & 769,500 & Broken \\
10 & 260 & 83,200 & Broken \\
11 & 260 & 92,500 & Broken \\
12 & 260 & 107,700 & Broken \\
$\mathbf{5 0} \times \mathbf{1 7 8}(\mathbf{m m})$ specimens, $\mathbf{R}=\mathbf{- 1 ,} \mathbf{V}=\mathbf{3 4 9 5 0 2 , 2} \mathbf{~ m m}^{\mathbf{3}}$ & & \\
1 & 190 & 295,000 & Broken \\
2 & 190 & 869,000 & Broken \\
3 & 190 & 869,000 & Broken \\
4 & 190 & $1,573,335$ & Broken \\
5 & 220 & 151,400 & Broken \\
6 & 220 & 152,000 & Broken \\
7 & 220 & 183,700 & Broken \\
8 & 220 & 218,000 & Broken \\
9 & 260 & 30,200 & Broken \\
10 & 260 & 45,100 & Broken \\
11 & 260 & 46,900 & Broken \\
12 & 260 & 47,300 & Broken \\
\hline
\end{tabular}


Table A3. Alternating torsion fatigue test data of JIS SUJ2/AISI 52100 steel at 6 nominal shear stress amplitudes $\tau_{a, n o m}$ by Shimizu et al. [4].

\begin{tabular}{|c|c|c|c|c|c|c|}
\hline \multirow[b]{2}{*}{ Specimen number } & \multicolumn{6}{|c|}{ Fatigue life $N$ (cycles) } \\
\hline & $\tau_{a, \text { nom }}=0.5 \mathrm{GPa}$ & $\tau_{a, \text { nom }}=0.63 \mathrm{GPa}$ & $\tau_{a, n o m}=0.76 \mathrm{GPa}$ & $\tau_{a, \text { nom }}=0.80 \mathrm{GPa}$ & $\tau_{a, \text { nom }}=0.95 \mathrm{GPa}$ & $\tau_{a, \text { nom }}=1.0 \mathrm{GPa}$ \\
\hline 1 & $5.42 \mathrm{E}+06$ & $8.65 \mathrm{E}+05$ & $1.23 \mathrm{E}+05$ & $6.30 \mathrm{E}+04$ & $1.20 \mathrm{E}+04$ & $3.28 \mathrm{E}+03$ \\
\hline 2 & $6.62 \mathrm{E}+06$ & $9.67 \mathrm{E}+05$ & $1.34 \mathrm{E}+05$ & $8.40 \mathrm{E}+04$ & $1.30 \mathrm{E}+04$ & $4.58 \mathrm{E}+03$ \\
\hline 3 & $7.63 \mathrm{E}+06$ & $1.09 \mathrm{E}+06$ & $1.78 \mathrm{E}+05$ & $1.03 \mathrm{E}+05$ & $1.60 \mathrm{E}+04$ & $5.77 \mathrm{E}+03$ \\
\hline 4 & $1.00 \mathrm{E}+07$ & $1.25 \mathrm{E}+06$ & $1.86 \mathrm{E}+05$ & $1.13 \mathrm{E}+05$ & $1.90 \mathrm{E}+04$ & $7.61 \mathrm{E}+03$ \\
\hline 5 & $1.00 \mathrm{E}+07$ & $1.35 \mathrm{E}+06$ & $2.30 \mathrm{E}+05$ & $1.17 \mathrm{E}+05$ & $2.10 E+04$ & $8.20 E+03$ \\
\hline 6 & $1.25 \mathrm{E}+07$ & $1.37 \mathrm{E}+06$ & $2.37 \mathrm{E}+05$ & $1.18 \mathrm{E}+05$ & $2.50 \mathrm{E}+04$ & $8.29 E+03$ \\
\hline 7 & $1.76 \mathrm{E}+07$ & $1.53 \mathrm{E}+06$ & $2.51 \mathrm{E}+05$ & $1.24 \mathrm{E}+05$ & $2.70 \mathrm{E}+04$ & $8.89 \mathrm{E}+03$ \\
\hline 8 & $2.23 \mathrm{E}+07$ & $1.74 \mathrm{E}+06$ & $2.57 \mathrm{E}+05$ & $1.47 \mathrm{E}+05$ & $2.80 \mathrm{E}+04$ & $9.56 \mathrm{E}+03$ \\
\hline 9 & $2.38 \mathrm{E}+07$ & $1.79 E+06$ & $2.65 \mathrm{E}+05$ & $1.47 \mathrm{E}+05$ & $2.90 \mathrm{E}+04$ & $1.17 \mathrm{E}+04$ \\
\hline 10 & $2.56 \mathrm{E}+07$ & $2.20 E+06$ & $2.70 \mathrm{E}+05$ & $1.49 \mathrm{E}+05$ & $3.40 E+04$ & $1.22 \mathrm{E}+04$ \\
\hline 11 & $2.71 \mathrm{E}+07$ & $2.21 \mathrm{E}+06$ & $3.08 \mathrm{E}+05$ & $1.88 \mathrm{E}+05$ & $3.70 E+04$ & $1.29 E+04$ \\
\hline 12 & $2.74 \mathrm{E}+07$ & $2.93 \mathrm{E}+06$ & $3.26 \mathrm{E}+05$ & $2.18 \mathrm{E}+05$ & $3.80 \mathrm{E}+04$ & $1.36 \mathrm{E}+04$ \\
\hline 13 & $2.88 \mathrm{E}+07$ & $3.01 \mathrm{E}+06$ & $3.35 \mathrm{E}+05$ & $2.30 \mathrm{E}+05$ & $3.80 \mathrm{E}+04$ & $1.39 \mathrm{E}+04$ \\
\hline 14 & $2.89 \mathrm{E}+07$ & $3.12 \mathrm{E}+06$ & $3.43 \mathrm{E}+05$ & $2.38 \mathrm{E}+05$ & $4.00 \mathrm{E}+04$ & $1.40 \mathrm{E}+04$ \\
\hline 15 & $3.27 \mathrm{E}+07$ & $4.42 \mathrm{E}+06$ & $3.63 \mathrm{E}+05$ & $2.55 \mathrm{E}+05$ & 4.10E+04 & $1.42 \mathrm{E}+04$ \\
\hline 16 & $3.33 \mathrm{E}+07$ & $4.74 \mathrm{E}+06$ & $3.68 \mathrm{E}+05$ & $2.88 \mathrm{E}+05$ & $4.20 \mathrm{E}+04$ & $1.52 \mathrm{E}+04$ \\
\hline 17 & $3.91 \mathrm{E}+07$ & $5.02 \mathrm{E}+06$ & $3.68 \mathrm{E}+05$ & $3.11 \mathrm{E}+05$ & $4.30 \mathrm{E}+04$ & $1.57 \mathrm{E}+04$ \\
\hline 18 & $4.22 \mathrm{E}+07$ & $5.25 \mathrm{E}+06$ & $4.22 \mathrm{E}+05$ & $3.44 \mathrm{E}+05$ & $4.50 \mathrm{E}+04$ & $1.76 \mathrm{E}+04$ \\
\hline 19 & $4.45 \mathrm{E}+07$ & $6.82 \mathrm{E}+06$ & $4.98 \mathrm{E}+05$ & $3.72 E+05$ & $4.70 \mathrm{E}+04$ & $1.84 \mathrm{E}+04$ \\
\hline 20 & $5.95 \mathrm{E}+07$ & & $5.11 \mathrm{E}+05$ & $4.41 \mathrm{E}+05$ & $5.10 \mathrm{E}+04$ & $1.85 \mathrm{E}+04$ \\
\hline 21 & & & $5.60 \mathrm{E}+05$ & $4.70 \mathrm{E}+05$ & $5.20 \mathrm{E}+04$ & $2.10 \mathrm{E}+04$ \\
\hline 22 & & & $5.64 \mathrm{E}+05$ & $4.97 \mathrm{E}+05$ & $5.50 \mathrm{E}+04$ & $2.45 \mathrm{E}+04$ \\
\hline 23 & & & $5.78 \mathrm{E}+05$ & $5.36 \mathrm{E}+05$ & $5.70 \mathrm{E}+04$ & $2.47 \mathrm{E}+04$ \\
\hline 24 & & & $6.08 \mathrm{E}+05$ & $5.72 \mathrm{E}+05$ & $6.60 \mathrm{E}+04$ & $2.76 \mathrm{E}+04$ \\
\hline 25 & & & $6.12 \mathrm{E}+05$ & $7.56 \mathrm{E}+05$ & $7.00 \mathrm{E}+04$ & $1.87 \mathrm{E}+04$ \\
\hline 26 & & & $6.13 \mathrm{E}+05$ & & & $3.78 \mathrm{E}+04$ \\
\hline 27 & & & $6.34 \mathrm{E}+05$ & & & $3.83 \mathrm{E}+04$ \\
\hline 28 & & & $6.49 \mathrm{E}+05$ & & & $4.68 \mathrm{E}+04$ \\
\hline 29 & & & $6.70 \mathrm{E}+05$ & & & \\
\hline 30 & & & $7.00 \mathrm{E}+05$ & & & \\
\hline 31 & & & $8.34 \mathrm{E}+05$ & & & \\
\hline 32 & & & $8.43 \mathrm{E}+05$ & & & \\
\hline 33 & & & $9.82 \mathrm{E}+05$ & & & \\
\hline
\end{tabular}

